\title{
MODOS DE CONSTRUIR Y HABITAR DURANTE MOMENTOS TARDOCOLONIALES EN LA PUNA DE JUJUY, ARGENTINA: EL CASO DE LA LOCALIDAD DE ANTIGUYOC
}

\author{
Marco Nicolás Giusta*
}

Fecha de recepción: 30 de octubre de 2020

Fecha de aceptación: 26 de mayo de 2021

\section{RESUMEN}

Se presentan los resultados e interpretaciones vinculados al estudio acerca de ocupaciones de origen tardocolonial que tuvieron lugar en las quebradas de Antiguyoc y del Maray, ambas comprendidas dentro de la localidad arqueológica de Antiguyoc (región de Puna de Jujuy, República Argentina). Las investigaciones se llevaron a cabo con el objetivo general de aportar al conocimiento sobre modos de construir y habitar en asentamientos del período colonial ubicados en yacimientos mineros altoandinos. Para alcanzarlo se puso énfasis en el análisis de los remanentes arquitectónicos y se articularon los datos arqueológicos con fuentes históricas inéditas y etnográficas. El estudio permitió identificar las características y variabilidad de la arquitectura en ambos asentamientos y generar interpretaciones acerca de la conformación social y las prácticas de los grupos que ocuparon los diferentes sectores analizados.

Palabras clave: hábitat - asientos mineros - arquitectura - Puna de Jujuy - Período tardocolonial

WAYS OF BUILDING AND INHABITING DURING LATE COLONIAL TIMES IN PUNA DE JUJUY, ARGENTINA: THE CASE OF ANTIGUYOC

\section{ABSTRACT}

Results and interpretations regarding the study of late colonial occupations that took place in the Antiguyoc and Maray gorges, both within the Antiguyoc archaeological locality (Puna de

\footnotetext{
* Instituto de Arqueología y Museo (Facultad de Ciencias Naturales e IML, Universidad Nacional de Tucumán, Argentina) e Instituto Superior de Estudios Sociales; Consejo Nacional de Investigaciones Científicas y Técnicas. Email: giustamarco@yahoo.com.ar
} 
Jujuy, Argentina) are presented. The general objective of this research is to contribute to the understanding of ways of building and living in settlements located in high Andean mining deposits during the colonial period. For this purpose, emphasis was set upon the analysis of architectural remains. Moreover, archaeological data was integrated with unpublished historical and ethnographic sources. This study allowed to identify the architectural variability and features in both settlements, and to propose interpretations about the social constitution and practices among the groups that occupied the different sectors under study.

Keywords: habitat - mining seats - architecture - Puna de Jujuy - Late colonial period

\section{INTRODUCCIÓN}

En este trabajo se presentan los resultados e interpretaciones vinculados al estudio que se llevó a cabo sobre los remanentes arquitectónicos de ocupaciones de momentos tardocoloniales y de transición hacia el período republicano que se desarrollaron en las quebradas de Antiguyoc y del Maray, próximas entre sí y comprendidas dentro de la localidad arqueológica de Antiguyoc (Puna de Jujuy, Argentina). Se expone parte de una investigación doctoral orientada a indagar acerca de los modos de construir y habitar que tuvieron lugar en este sector altoandino durante un lapso aproximado de 50 años (ca. 1774-1824), tiempo durante el cual los sitios analizados funcionaron como asientos mineros, hacienda hispana y Viceparroquia (Ulloa 2005; Giusta 2019).

\section{Breves antecedentes}

Dentro de los estudios de vivienda y asentamientos del período colonial en América, ha existido una tendencia hacia el enfoque de lo que fueron grandes ciudades hispanas, con el objetivo de analizar sus configuraciones internas, el modo en que fueron evolucionando y las maneras mediante las cuales se impusieron determinados patrones urbanísticos (cfr. Domínguez 1948; Zapata Gollán 1981; Gutiérrez 1983; Schávelzon 1994; Gisbert y Mesa 1997; Hardoy y Gutman 2001; Silva 2001; Jamieson 2003; Carmignani 2018; Urbina et al. 2018a; Niell 2019; entre otros). En estos casos, el estudio de la vivienda estuvo orientado principalmente hacia las propiedades del segmento social urbanizado y, por lo general, a las zonas en las que se asentaba la población con mejores condiciones económicas, mientras que resultan más reducidos los análisis sobre barrios o sectores suburbanos, lugares de asiento de población indígena y las denominadas "castas". Como señalan Rivet y Tomasi (2009), esto dio lugar a una imagen estereotipada de la vivienda colonial. ${ }^{1}$ Asimismo, resulta por lo general escaso el tratamiento que se le dio en estas obras a los asentamientos rurales y pueblos de indios. Cuando se lo hizo, se puso énfasis en edificaciones singulares como iglesias y estancias o haciendas hispanas, lo cual generó contrastes en el conocimiento que se tiene acerca de las diversas arquitecturas coloniales y originó desiguales procesos de patrimonialización y/o protección (para la provincia de Jujuy, cfr. Herr y Rolón 2018; Tomasi y Barada 2020). Durante un tiempo la arqueología no estuvo alejada de esta dirección ya que las investigaciones del período colonial, al menos en el actual territorio argentino, se concentraron principalmente en lo que fueron áreas urbanas (cfr. Biró de Stern 1945; Zapata Gollán 1956; Gramajo de Martínez 1976; Morresi 1983; Schávelzon 1988, 1999; Bárcena y Schávelzon 1991; Rivet 2017; entre otros). El aspecto positivo es que dichos aportes no solo contribuyeron al conocimiento del mencionado período desde los aspectos materiales, sino que, en el caso de Argentina, afianzaron el campo de la Arqueología Histórica (Raffino e Igareta 2003). De ese modo, desde esta esfera disciplinar se comenzó a poner cada vez mayor atención en el estudio de espacios rurales o alejados de las ciudades (cfr. Quiroga 1999, 2007; Tapia 2002; Lema 2004, 2012; Tapia 
et al. 2006; Bianchi Villelli 2009; Becerra 2012, 2014a, 2014b; Buscaglia et al. 2012; Mignone 2014; Taboada y Faberman 2014; Faberman y Taboada 2018; entre otras).

En nuestra área de estudio, los trabajos arqueológicos sobre el período colonial emprendidos por el equipo dirigido por C. Angiorama partieron de la base proporcionada por investigaciones históricas (cfr. Palomeque 1995, 2006; Gil Montero 1997, 2004; Ulloa 2005; entre otras). Los resultados permitieron redimensionar planteos generados desde el análisis de fuentes escritas y con ello aportar conocimiento acerca de las particularidades de la presencia humana en el área (cfr. Angiorama y Becerra 2012; Becerra 2012, 2014a; Pérez Pieroni 2015, 2018; Angiorama et al. 2018b; entre otros). Se propuso que, si bien la minería de la Puna jujeña alcanzó desarrollos de baja escala en comparación, por ejemplo, con yacimientos del actual sur boliviano, se convirtió en una actividad transcendental de la época ya que atravesó gran parte de los aspectos económicos, sociales y políticos e introdujo modificaciones sustanciales en el paisaje (cfr. Becerra 2012, 2014a, 2014b; Angiorama et al. 2015, 2018a, 2018b, 2019; Becerra y Estruch 2016). Una de estas transformaciones consistió en la construcción de numerosos y variados asentamientos en las adyacencias de las zonas de laboreo minero (Angiorama y Becerra 2012).

El espacio y el tiempo: la Puna de Jujuy en el período colonial, la localidad de Antiguyoc y los sitios estudiados

Se conoce como Puna de Jujuy al sector septentrional de la Provincia de Jujuy, en el extremo noroccidental de la República Argentina, que forma parte del sector meridional del altiplano andino. En las sierras de Carahuasi y Rinconada, y su prolongación hacia el norte (Sierra de Santa Catalina), se localizan numerosos depósitos de minerales metalíferos como oro, plata, plomo, estaño y zinc, entre otros (Alonso y Viramonte 1987; Coira et al. 2004). Algunos de ellos, como Coyahuaima y Timón Cruz, podrían habrían sido explotados desde épocas prehispánicas (Angiorama y Becerra 2014; Angiorama et al. 2019), aunque las evidencias no son aún del todo claras. En cambio, como hemos señalado, la minería durante el período colonial está ampliamente comprobada.

La instalación europea comenzó a concretarse de manera efectiva hacia fines del siglo XVI, facilitada por la última fundación de la ciudad de Jujuy y por las mercedes de tierras concedidas por la Corona (Albeck y Palomeque 2009). El siglo XVII estuvo caracterizado por la "pacificación” y reducción de una porción de la población indígena, el comienzo de la actividad evangelizadora y la apropiación del territorio e inicio de emprendimientos económicos por parte de españoles. En el siglo XVIII, en especial desde la segunda mitad, en nuestra área de estudio se observa un aparente repunte de la actividad minera, al igual que en otras zonas del espacio andino (Fisher 2000; Madrazo 2005), y un incremento de la estructura y presencia eclesiástica a partir de la creación de varias parroquias y viceparroquias, algunas de las cuales se ubicaron en asientos mineros como Rinconada, Santa Catalina, Santo Domingo y el propio Antiguyoc.

En este contexto, algunos empresarios españoles o criollos no solo se volcaron a la actividad minera, sino también ganadera, mediante el papel de proveedores de insumos hacia minas del Alto Perú (Sánchez Albornoz 1965; Paz 1997; Assadourian y Palomeque 2015). Tal es el caso de Fernando Dávalos quien, de acuerdo con la documentación escrita disponible, inició alrededor del año 1775 en Antiguyoc un emprendimiento que incluía extracción aurífera y matanza de ganado, cuyos productos eran trasladados en parte hacia Potosí ${ }^{2}$ (Ulloa 2005). Las investigaciones históricas y etnohistóricas señalan que en este lugar funcionó el asiento y la viceparroquia de Antiguyoc (Palomeque 1995; Gil Montero 2004).

La localidad de Antiguyoc está ubicada sobre el faldeo occidental de la Sierra de Carahuasi (actual departamento Rinconada; figura 1), a más de 4.000 m s.n.m., y constituye uno de los distritos auríferos de la región (Cabanettes y Amans 1891; Sgrosso 1943; Angelelli 1984). Las 
investigaciones que presentamos en esta ocasión se concentraron en dos sectores, distanciados entre sí por $2 \mathrm{~km}$ : las quebradas de Antiguyoc (AN) y del Maray (QM), ambas con cursos de agua tributarios del río Ajedrez (figura 1). Allíllevamos a cabo prospecciones arqueológicas y registro de evidencias materiales superficiales de ocupación humana, las cuales consisten en construcciones, vestigios muebles y remanentes de explotaciones mineras.

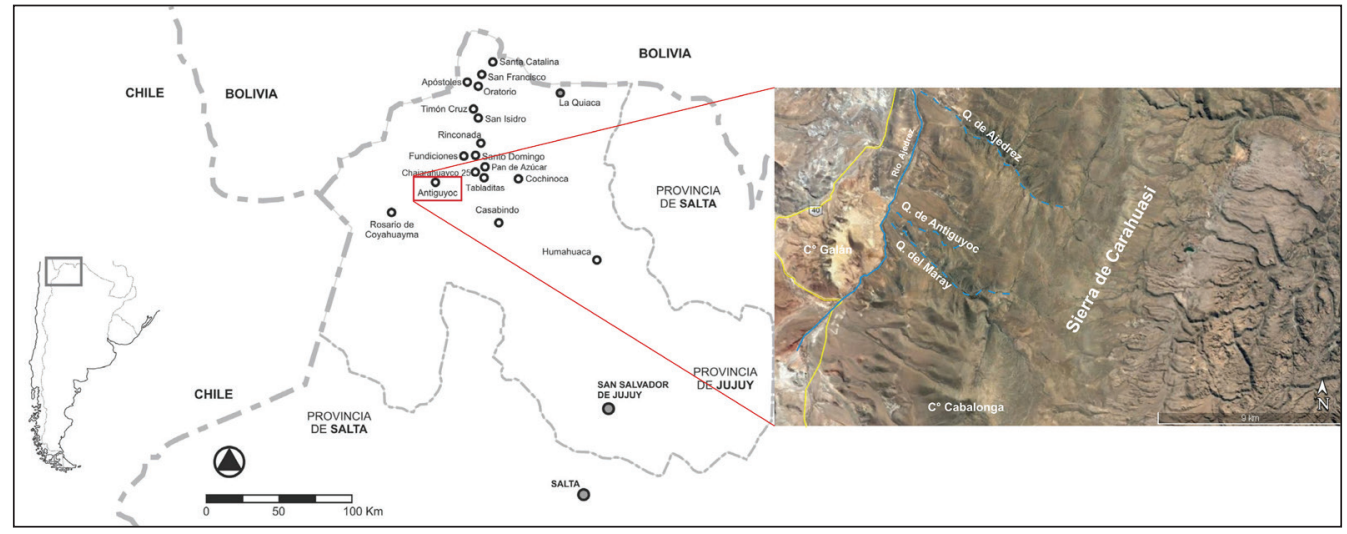

Figura 1. Ubicación del área de estudio. Fuente: mapa e imagen satelital tomados y modificados de Becerra (2014b) y Google Earth, respectivamente

En AN registramos tres sectores con arquitectura, a los cuales denominamos Antiguyoc 1, 4 y 7 (en adelante AN1, AN4 y AN7). En total determinamos la presencia de veintitrés conjuntos arquitectónicos ${ }^{3}$ (en adelante $\mathrm{CA}$ ) y ocho recintos aislados. La principal concentración de construcciones se encuentra en AN1, donde se disponen veintiún CA y ocho recintos aislados dentro de un área de $400 \mathrm{~m}$ por $200 \mathrm{~m}$. A su vez, allí se encuentran numerosas evidencias de explotaciones mineras consistentes en piques, socavones, trincheras y desmontes, las cuales se disponen también a lo largo de toda la quebrada. AN1 está conformado por un núcleo constructivo central en el que destacan una iglesia y un espacio despejado al frente, mientras que a $200 \mathrm{~m}$ de allí se ubica un cementerio, a la vera del camino por el que se accede actualmente al sitio (figura 2).

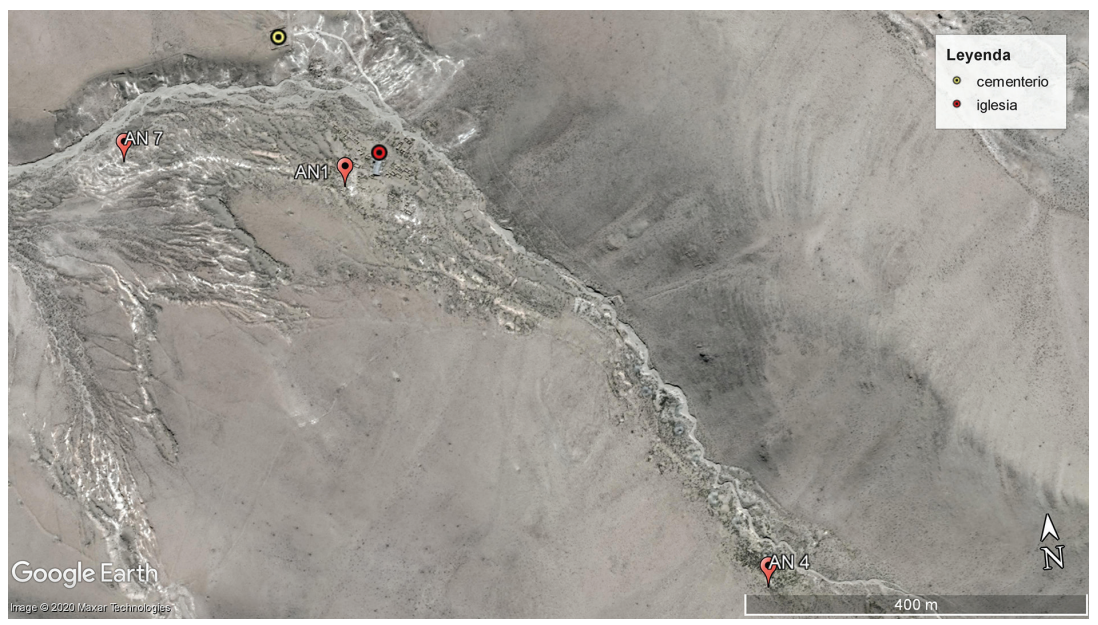

Figura 2. Vista parcial de la quebrada de Antiguyoc con ubicación de los sectores analizados en este trabajo. Fuente: imagen satelital tomada y modificada de Google Earth 
En QM registramos evidencias arqueológicas sobre el sector superior de la terraza izquierda del curso de agua que agrupamos bajo la denominación de Quebrada del Maray 4 (en adelante QM4). Fue sectorizado según características de las construcciones y su distribución espacial (figura 3). El Sector A (SA) consta de tres CA, dentro de los cuales destaca el $n^{\circ} 1$, consistente en un polígono irregular delimitado por muros que circunscriben un espacio de $75 \mathrm{~m}$ por $55 \mathrm{~m}$ en sus lados más largos, con numerosos recintos en su interior. Hacia el oeste y noroeste del sector anterior se encuentran once CA y tres recintos aislados que fueron agrupados dentro del Sector B (SB). Éstos se disponen espaciados irregularmente y de manera alineada en sentido noroeste-sureste a lo largo de $260 \mathrm{~m}$. El Sector C (SC) se ubica a $275 \mathrm{~m}$ hacia el sur del SA. Está integrado por un CA y un recinto aislado, distanciados entre sí por $70 \mathrm{~m}$. El Sector D (SD) comienza a una distancia de $400 \mathrm{~m}$ hacia el sureste del sector anterior. A lo largo de $200 \mathrm{~m}$ se disponen de manera dispersa siete CA y un recinto aislado. Todas las construcciones se encuentran próximas a evidencias de laboreos mineros (pozos, trincheras, desmontes y plataformas), en especial aquellas ubicadas en los sectores B, C y D. A diferencia de lo que sucede en AN, no hemos registrado hasta el momento piques o socavones para extracción de oro en veta, por lo que las tareas se habrían restringido a la extracción y lavado de sedimentos auríferos.

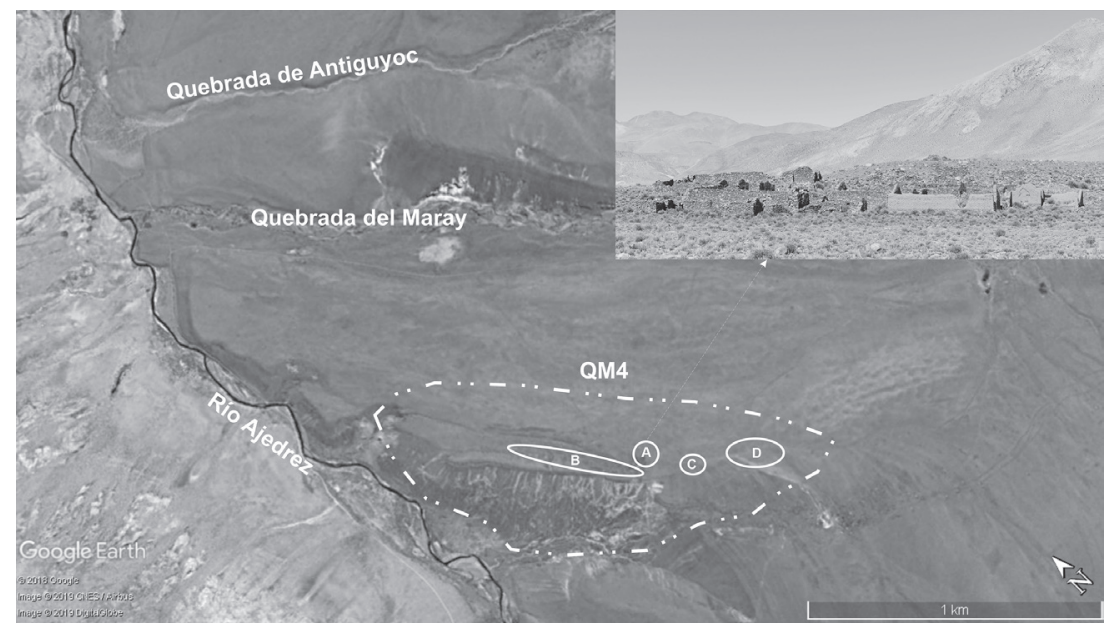

Figura 3. Ubicación de QM4 con distribución de los sectores, y vista del Sector A desde el este. Fuente: imagen satelital tomada y modificada de Google Earth

Si bien las fuentes históricas consultadas refieren a lugares como Antiguyoc, Nuestra Señora del Carmen de Antiguyoc, Maray y otros topónimos similares, éstas no indican de manera explícita la existencia de dos asentamientos durante el período de dominación hispana. Esto motivó una serie de interrogantes que se transformaron en objetivos de investigación, algunas de las cuales abordamos en el presente trabajo: cómo estuvieron conformados internamente los poblados y en función de qué actividades; quiénes son las personas que vivieron allí y qué tipos de prácticas llevaron a cabo; y qué podemos inferir acerca de las relaciones sociales entre sus habitantes.

\section{ASPECTOS TEÓRICO-METODOLÓGICOS}

Partimos de la premisa de que desde el estudio de la arquitectura y su ordenamiento espacial es factible generar propuestas e interpretaciones sobre las personas que construyeron y utilizaron las edificaciones, y sus prácticas e interacciones sociales (Mañana Borrazás et al. 2002; Criado 
Boado y Mañana Borrazás 2003; Vaquer 2010, 2012; entre otros). Concebimos las edificaciones como objetos complejos y multifuncionales que poseen una dualidad física y espacial, ya que en su creación son construidos tanto el objeto arquitectónico en sí mismo como también el espacio delimitado por éste (Hillier y Hanson 1984; Hillier 1996). A su vez, en este proceso el espacio no solo es creado, sino ordenado y transformado. Es decir que si hablamos de edificaciones no solo nos referimos a productos materiales, sino a sistemas de relaciones espaciales (Hillier y Hanson 1984). En este sentido, los productos y sistemas resultantes del acto constructivo no representan simplemente la sociedad que los crea y usa, sino que "Architectural space is one of the primary means through which society is directly constituted" (Ferguson 1996:3, resaltado en el original). Por lo tanto, el ordenamiento del espacio mediante construcciones expresa de alguna manera el ordenamiento de relaciones entre personas.

Lo expresado es factible de aplicar en el plano de los análisis e interpretaciones arqueológicas ya que, tal como lo señalaron numerosos autores, los espacios creados por las personas mediante la arquitectura y la manera de ordenarlos o distribuirlos habilitan o restringen (también se ha expresado que "alientan o desalientan", sensu Vaquer 2012) ciertas interacciones y prácticas sociales (cfr. Hillier y Hanson 1984; Nielsen 1995; Ferguson 1996; Vaquer 2010, 2012; entre otros). En este sentido, para proponer interpretaciones sobre la funcionalidad/uso de los espacios y a su vez asociarlos con modelos que vinculan el ordenamiento espacial con las interacciones sociales, resulta necesario, en primer lugar, conocer cómo está constituido un asentamiento desde un punto de vista formal, es decir, qué tipos de edificaciones existen, las técnicas y materiales utilizados para su construcción, y los rasgos arquitectónicos presentes. Esta información permite aproximarnos a las características de performance (Nielsen 1995; Schiffer 1999) de los elementos construidos, entendido este término como "the behavioral capabilities that artifacts possess by virtue of their design" (Nielsen 1995:52), lo cual implica que entre las prácticas y los agentes que las llevan a cabo existe un tercer factor, constituido por los elementos involucrados y sus características materiales (Vaquer 2010). Esto significa que el diseño y ejecución que registramos en las construcciones, junto con los rasgos arquitectónicos y otro tipo de estructuras asociadas preservadas, son tomados como indicativos de las actividades para las cuales podrían haber estado destinadas. A su vez, algunas de estas interpretaciones se apoyan sobre la base de las funciones de construcciones similares que se registraron arqueológica y etnográficamente en la Puna de Jujuy y áreas circundantes.

\section{Materiales y métodos}

Llevamos a cabo un registro pormenorizado de la arquitectura, analizamos las técnicas constructivas y la manera en que se disponen y organizan los volúmenes resultantes, es decir los espacios construidos. En primer lugar, realizamos la planimetría de cada asentamiento y luego se profundizó el registro de la arquitectura, para lo cual se utilizó como referencia la propuesta de Castro et al. (1991), adaptando las variables de registro y sus estados a las características de los sitios y nuestros objetivos.

Se consignaron datos correspondientes a atributos de las plantas, muros, cubiertas, componentes constructivos y rasgos arquitectónicos, como así también las relaciones estratigráficas murarias (en base a Parenti 1988). Las principales variables consideradas son sintetizadas en la tabla 1.

En la etapa de registro se tuvo en cuenta naturaleza, tamaños, formas y trabajo de los componentes constructivos principales, es decir los materiales utilizados en la construcción (Rolón 2013), como ser mampuestos, mortero, revestimientos, entre otros. Por otro lado, se registraron atributos de los elementos constructivos, es decir, el "conjunto de componentes materiales o constructivos que, actuando de manera indivisible, constituyen una parte del sistema mayor o construcción" (Rolón 
2013:126). En este caso pusimos énfasis en los muros y las modalidades de techado o cubierta que están presentes o bien que pueden ser inferidas. Se registraron dimensiones de longitud, ancho y alturas máxima y mínima conservadas en los muros y se consideró la disposición u ordenamiento de los componentes constructivos (tipo de aparejo, cantidad de hileras, aplomo, etc.). Las plantas de los recintos se registraron según su morfología, dimensiones y superficie interna. Las formas fueron determinadas de acuerdo a su asociación o similitud con figuras geométricas. También registramos la presencia de rasgos arquitectónicos, es decir, elementos presentes en los muros o adosados, la mayoría de los cuales se presentan como elementos fijos (sensu Rapoport 1990). Se consideró el tipo de rasgo, cantidad, dimensiones, forma, ubicación y materiales utilizados. Por último, se consignaron estado de conservación y observaciones generales. El registro escrito fue acompañado por croquis a mano alzada y fotografías.

Tabla 1. Síntesis de las principales variables consideradas en el registro arquitectónico

\begin{tabular}{|c|c|}
\hline GRUPO & VARIABLE \\
\hline \multirow{3}{*}{ PLANTAS } & Dimensiones \\
\hline & Forma \\
\hline & Orientación \\
\hline \multirow{5}{*}{ MUROS } & Dimensiones \\
\hline & Tipo de aparejo \\
\hline & Hileras \\
\hline & Aplomo \\
\hline & Estado de conservación \\
\hline CUBIERTA & Tipo de cubierta \\
\hline \multirow{6}{*}{ COMPONENTES CONSTRUCTIVOS } & Naturaleza de mampuestos \\
\hline & Tamaños de mampuestos \\
\hline & Forma de mampuestos \\
\hline & Trabajo en mampuestos \\
\hline & Tipo de mortero \\
\hline & Tipo de revestimiento \\
\hline \multirow{6}{*}{ RASGOS ARQUITECTÓNICOS } & Tipo de rasgo \\
\hline & Cantidad \\
\hline & Dimensiones \\
\hline & Forma \\
\hline & Materiales \\
\hline & Ubicación \\
\hline
\end{tabular}

Fuente: elaboración del autor.

\section{RESULTADOS}

En primer lugar, trataremos los resultados referentes al análisis de los recintos, a los cuales consideramos como espacios construidos continuos, comprendidos dentro de límites definidos por elementos constructivos (Wynveldt 2005). Presentan una delimitación perimetral completa, la mayoría de las veces solo interrumpida por vano/s de acceso. El universo de estudio comprendió una totalidad de 192 recintos (103 registrados en AN y 89 en QM4). El estado de conservación 
de la arquitectura permitió, en la mayoría de los casos, identificar cuáles pudieron presentar techumbre y determinar o inferir el tipo de cubierta. De este modo, para presentar sus características arquitectónicas tomaremos esta primera clasificación, es decir entre aquellos que hemos determinado como techados, por un lado, y los que no habrían estado cubiertos, por otro. A su vez, la combinación de estos atributos con el resto de las propiedades analizadas nos permitió evaluar la variabilidad en el interior de estas dos categorías.

Luego se presentan los espacios que denominamos anexos, aquellos en los que no existe una delimitación completa mediante elementos constructivos, por lo que podríamos caracterizarlos como espacios semicerrados (Rolón 2013). Se registraron 40 espacios anexos entre ambos sitios, 28 en AN y 12 en QM4.

Por último, y de manera complementaria, presentamos evidencias de lo que habrían sido estructuras de combustión asociadas a los recintos y anexos.

\section{Recintos tipo 1 (techados)}

Se registraron recintos con tres tipos de cubiertas: a dos aguas, a un agua y en falsa bóveda. El techado a dos aguas (recintos 1.A) pudo ser inferido a partir de la presencia de hastiales o mojinetes (sensu Schávelzon y Magadán 1992), los cuales sirven como parte de sostén para la estructura del techo y dictan la pendiente de la cubierta (figura 4.A). Éstos se ubican en muros paralelos, que por lo general corresponden a los muros laterales y más cortos. El techado en falsa bóveda (sensu Ching 1996; clasificados como recintos 1.B) se realizó utilizando principalmente rocas planas dispuestas de manera horizontal, aparentemente sin argamasa, en avance entre una hilada y la anterior, es decir parcialmente superpuestas hacia el centro del recinto hasta cubrirlo completamente (figura 4.B). Los muros son de piedra unidas con argamasa de barro, y por lo general se presentan levemente desaplomados hacia el interior, en especial las hiladas superiores. En algunos casos el techo se conserva prácticamente íntegro, pero en otros solo permanece un segmento superior de los muros desaplomados, el dintel del vano de ingreso y gran cantidad de rocas de derrumbe en el interior, que habrían formado parte de la cubierta. Por último, la presencia de techumbres a un agua (recintos de tipo 1.C) no es del todo clara, pero su posibilidad está dada por el registro de recintos sin hastiales en los que uno de los muros exhibe mayor altura que su paralelo, posibilitando una única pendiente o caída (figura 4.C).

Fue posible determinar la presencia de 120 recintos que pudieron haber estado techados ( $n=71$ en AN; y n=49 en QM4). En AN, tres de ellos corresponden al CA de la iglesia (nave, campanario y sacristía). A su vez, son 12 los recintos ( $n=3$ en AN y n=9 en QM4) para los cuales no hemos podido determinar con certeza si contaron con una cubierta o no.

\section{Componentes y elementos constructivos}

Considerando los componentes constructivos, se registraron dos tipos básicos de muros para la construcción de recintos cubiertos: de piedra con argamasa de barro, y de adobes con argamasa de barro y sobrecimiento de piedra. Si exceptuamos las singulares resoluciones de las edificaciones correspondientes a la iglesia, en AN únicamente se registraron construcciones que estuvieron techadas a dos aguas, con muros en piedra. En QM4 se registraron las dos variantes, pero predomina ampliamente la construcción en piedra. Únicamente se registraron muros de adobe con sobrecimientos de piedra en el CA1 (SA).

Para las construcciones en piedra se utilizaron las rocas disponibles en el área. ${ }^{4}$ Se optó por bloques de entre 0,25 a $0,30 \mathrm{~m}$ de ancho y hasta $0,80 \mathrm{~m}$ de largo, es decir que se ubican en los 

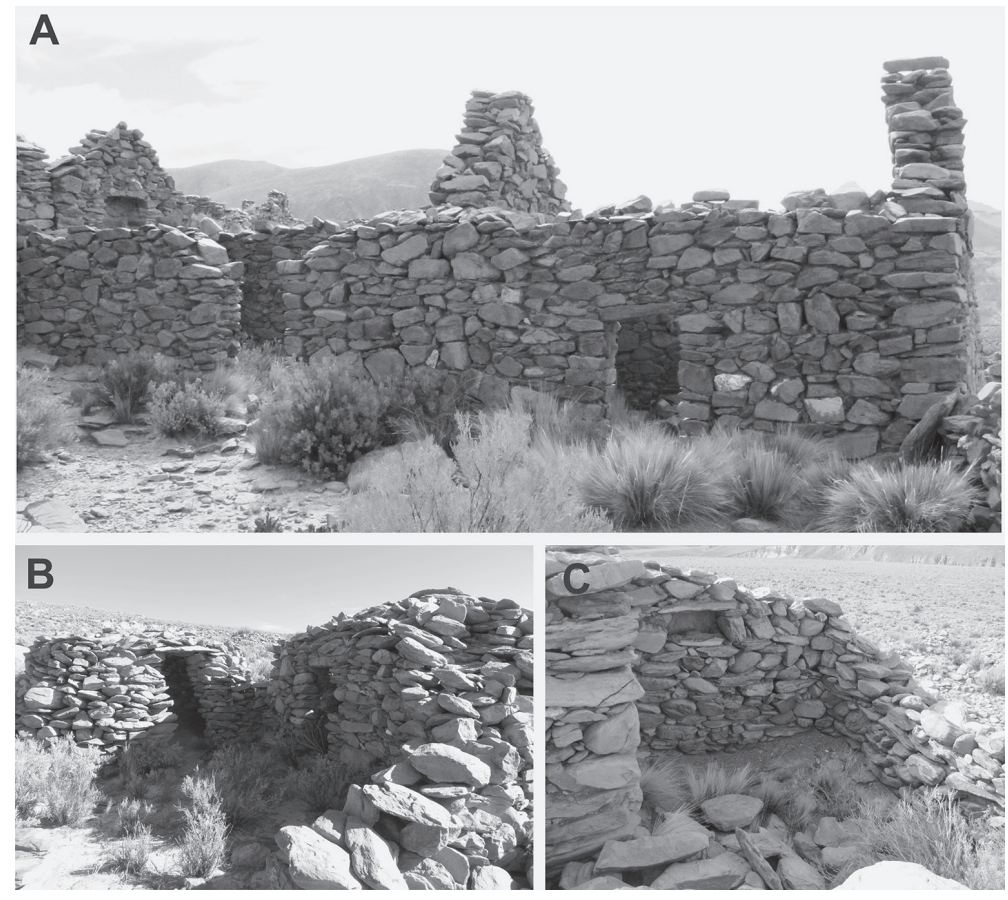

Figura 4. A: Unidad arquitectónica que estuvo cubierta a dos aguas. B: Recintos que aún conservan el techo en falsa bóveda. C: Recinto que habría estado cubierto a un agua. Fuente: elaboración del autor

tamaños pequeño, mediano y grande, de acuerdo con las categorías propuestas por Castro et al. (1991); con una predominancia en el rango intermedio (0,20 a 0,40 m). En la mayoría de los casos las rocas utilizadas no fueron trabajadas (canteadas o desbastadas) antes de su colocación, pero sí es posible notar una selección y orientación de caras planas, tanto para los lienzos internos como externos. La norma observada en la construcción de los muros de piedra es la disposición de dos hileras de rocas y la utilización de argamasa para generar muros cuyo ancho por lo general se ubica entre 0,50 y 0,65 m. En algunos sectores, principalmente en el encuentro de dos muros que traban en un vértice y en los márgenes de los vanos, algunos mampuestos se colocaron atravesando ambos lienzos. La altura de la cumbrera de los hastiales oscila entre 2,7 $\mathrm{m}$ y 3,6 m, mientras que los muros sin hastiales son entre $1 \mathrm{~m}$ y 1,5 m más bajos. Al parecer estas construcciones se realizaron siempre de manera aplomada, pero actualmente puede notarse desaplome en algunos de los muros, principalmente en aquellos con hastiales, seguramente por el peso que ejerció la techumbre. El material usado como mortero o argamasa, a partir de lo observado a simple vista, se realizó conformando una matriz de barro con la inclusión principal de pequeños guijarros, y en menores proporciones elementos como restos óseos, restos vegetales (maderas y endocarpos de durazno), fragmentos de cerámica y vidrio.

Los muros en piedra presentan aparejos rústicos, en algunos casos con la presencia de sectores con aparejo de tipo sedimentario (sensu Castro et al. 1991) (figura 5.A). Existió una tendencia a disponer los bloques de manera columnar en vértices de dos muros que traban y en vanos de puerta, procurando tal vez mayor estabilidad estructural en dichos sectores. A su vez, identificamos una variante que consistió en incorporar rocas de manera oblicua, cuya disposición más regular se dio en la técnica de opus spicatum o espina de pez (figura 5.B). En cambio, en otros recintos con rocas oblicuas no se observa claramente su aplicación (figura 5.C). Con respecto al adobe, de acuerdo con lo que se observa a simple vista, los ladrillos utilizados en QM4 fueron confeccionados con 
una mezcla de barro y una gran cantidad de guijarros, y se dispusieron en hilera simple, a tizón (figura 5.D). Los sobrecimientos de piedra presentan alturas de hasta 0,55/0,60 $\mathrm{m}$ de altura y 0,55 a 0,57 m de ancho. Estas bases de piedra evitan la erosión de los adobes (Schilman y Reisner 2011) y cuando son más anchas que los muros les aportan estabilidad. En la nave de la iglesia de AN1, en cambio, los ladrillos de adobe se presentan en una porción superior de los muros, los cuales son principalmente de piedra (figura 5.E).
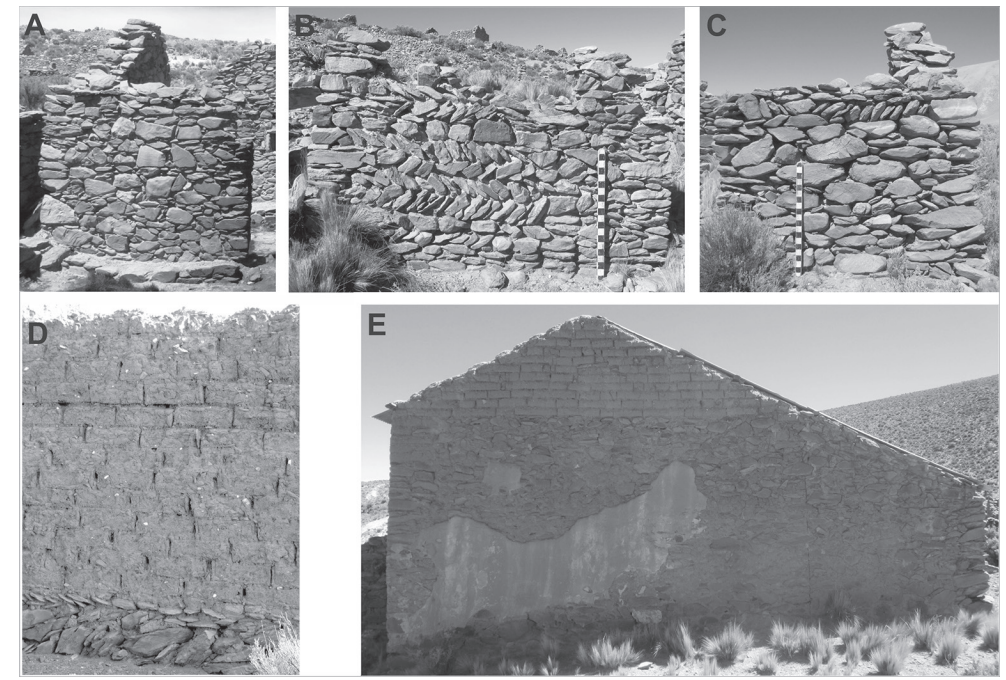

Figura 5. Ejemplos de tipos de aparejos. A: Rústico. B: Espina de pez. C: Rústico con hilada de rocas oblicuas. D: A tizón con adobes. E: Vista posterior de la iglesia, donde se observa el muro mixto de la nave. Fuente: elaboración del autor

En ciertos recintos se conservaron en algunos de sus muros internos segmentos con revestimiento consistente en revoque de barro y, en algunos casos, también tratamientos superficiales que podrían corresponder a enlucidos. Su conservación se manifiesta, por lo general, en sectores asociados a rasgos arquitectónicos que actuaron de protección, como el interior de nichos, vanos, y debajo de estantes de lajas. En QM4 el revoque en muros se limita a cinco recintos (10,2\% de los recintos tipo 1), todos ubicados en el CA1, de los cuales cuatro corresponden al subtipo 1.A.m. En AN se presenta de manera más extendida ya que fue registrado en 24 recintos $(33,8 \%$ de los recintos tipo 1).

La presencia de tratamiento superficial sobre el revoque resulta más limitada: en QM4 únicamente uno de los recintos del tipo 1.A.m podría haber contado con un enlucido, mientras que en AN solo se observó en cinco recintos de AN1.

En síntesis, si tenemos en cuenta los atributos considerados hasta aquí (componentes y elementos constructivos), podemos señalar que predominan aquellos recintos que estuvieron construidos con muros de piedra y techados a dos aguas (subtipo 1.A.r). Esta modalidad se da en prácticamente todos los espacios que habrían estado cubiertos de AN y en la mayor parte de los ubicados en QM4. La techumbre a dos aguas también se presenta en construcciones de muros mixtos, es decir, de adobe y piedra (subtipo 1.A.m), aunque en proporciones más bajas. Los muros en piedra se utilizaron además para construcciones con las otras dos modalidades de cubierta, es decir en falsa bóveda (tipo 1.B) y a un agua (tipo 1.C), las cuales se registraron únicamente en QM (tabla 2). 
Tabla 2. Cuantificación y distribución de los espacios construidos en los sitios AN y QM4 de acuerdo con la clasificación propuesta

\begin{tabular}{|c|c|c|c|c|c|c|c|c|c|c|c|c|}
\hline \multirow{3}{*}{$\begin{array}{l}\text { Sitio y } \\
\text { sector }\end{array}$} & \multicolumn{9}{|c|}{ RECINTOS } & \multicolumn{2}{|c|}{ ANEXOS } & \multirow{3}{*}{ TOTAL } \\
\hline & \multicolumn{4}{|c|}{ Techados } & \multicolumn{4}{|c|}{ No techados } & \multirow[b]{2}{*}{ Indet. } & \multirow{2}{*}{ tipo 1} & \multirow{2}{*}{ tipo 2} & \\
\hline & 1.A.r & 1.A.m & 1.B & 1.C & 2.A & 2.B & 2.C & 2.D & & & & \\
\hline AN1 & 66 & 1 & - & - & 2 & 11 & 2 & 11 & 3 & 16 & 8 & 120 \\
\hline AN4 & 2 & - & - & - & - & 1 & - & 2 & - & 3 & - & 8 \\
\hline AN7 & 1 & - & - & - & - & - & - & - & - & - & 1 & 2 \\
\hline Sub-total AN & 69 & 1 & - & - & 2 & 12 & 2 & 13 & 3 & 19 & 9 & 130 \\
\hline QM4 - S.A & 17 & 6 & - & 3 & 7 & 3 & - & - & - & 1 & 1 & 38 \\
\hline QM4 - S.B & 10 & - & 3 & 1 & 3 & 7 & - & - & 7 & 6 & 2 & 39 \\
\hline QM4 - S.C & - & - & 1 & - & - & - & 1 & - & 1 & - & - & 3 \\
\hline QM4 - S.D & - & - & 8 & - & 2 & 3 & - & 5 & 1 & - & 2 & 21 \\
\hline Sub-total QM4 & 27 & 6 & 12 & 4 & 12 & 13 & 1 & 5 & 9 & 7 & 5 & 101 \\
\hline TOTAL & 96 & 7 & 12 & 4 & 14 & 25 & 3 & 18 & 12 & 26 & 14 & 231 \\
\hline
\end{tabular}

Fuente: elaboración del autor.

Modalidades constructivas de las unidades arquitectónicas

Denominamos unidad arquitectónica (en adelante UA) a una construcción con un perímetro definido en la que la unidad de los componentes y elementos constructivos que la conforman permiten identificarla como un todo singular, producto de una única voluntad constructiva. Se identificaron dos configuraciones básicas: aquellas que están conformadas por un único recinto o ambiente, a las que llamamos unidades arquitectónicas simples (en adelante, UAS), y las que presentan más de un ambiente, a las cuales denominamos unidades arquitectónicas compuestas (en adelante, UAC). Éstas se caracterizan por contener uno o más muros internos que permitieron la conformación de al menos dos recintos. Los recintos que las componen en su gran mayoría estuvieron techados, pero también registramos tres UA conformadas por un recinto que estuvo cubierto y otro descubierto, a las cuales hemos denominado UAC mixtas.

En AN, los recintos tipo 1 se presentan como UAS en 42 casos $(59,2 \%)$, mientras que conforman UAC en 29 ocasiones (40,8\%). En QM4 son $34(69,4 \%)$ los recintos que conforman UAS y $15(30,6 \%)$ se presentan conformando UAC. Ahora bien, dentro de las UAC, las relaciones estratigráficas entre los muros nos permitieron distinguir dos modalidades constructivas:

Modalidad I: El muro interno que divide los recintos se apoya en los muros perimetrales, por lo que se trata de un espacio inicial que fue subdividido. En la amplia mayoría de los casos, esta división se hizo mediante un muro tipo "tabique", es decir, no portante (figura 6.A).

Modalidad II. En esta modalidad, el muro que divide los recintos se une trabando con muros perimetrales de la UA, lo que nos permite saber que su construcción fue contemporánea al resto de la unidad. En este sentido, podemos afirmar con seguridad que la construcción fue realizada para contener, al menos, dos espacios iniciales. El muro interno, en este caso, siempre es de tipo portante, con hastial. A su vez registramos dos variantes según la manera en que se vinculan los recintos entre sí y con el exterior:

- Variante II.a: los recintos se encuentran comunicados entre sí internamente. Las UA rectangulares adquieren una fisonomía similar a la Modalidad I, ya que también poseen un único vano de acceso (figura 6.B). 
- Variante II.b: se trata de UA en las que los recintos son independientes entre sí ya que no presentan comunicación interna (figura 6.C).

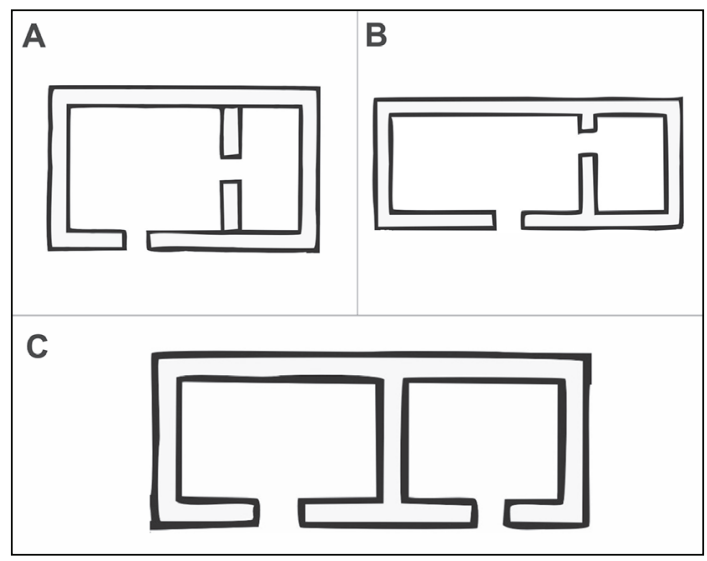

Figura 6. Plantas esquemáticas de las modalidades constructivas de las UAC.

A: Modalidad I. B: Modalidad II.a. C: Modalidad II.b. Fuente: elaboración del autor

Sintetizando los tipos y modalidades constructivas identificados, podemos indicar que en AN la única modalidad de techado registrada es de tipo 1.A, presente en la arquitectura de todos los sectores (AN1, AN4 y AN7). La única excepción estaría dada por la torre de campanario de la iglesia, construcción singular que presenta un techo piramidal o a cuatro aguas. Las UAC se encuentran exclusivamente en AN1 y están integradas, en todos los casos, por dos recintos. De las quince registradas (treinta recintos), catorce están conformadas únicamente por recintos techados, mientras que la restante es de tipo mixta. Nueve corresponden a la Modalidad I y seis a la II, con sus dos variantes (II.a y II.b, con tres casos cada una). En QM4 predominan los recintos del tipo 1.A ( $N=33)$, presentes en los sectores $A(n=23$, de los cuales 17 son del subtipo 1.A.r y 6 del subtipo 1.A.m; donde el CA1 nuclea a 21 de los 33) y $\mathrm{B}(\mathrm{n}=10)$; luego siguen los de tipo 1.B $(\mathrm{N}=12)$, los cuales se ubican en los sectores $\mathrm{B}(\mathrm{n}=3), \mathrm{C}(\mathrm{n}=1)$ y $\mathrm{D}(\mathrm{n}=8)$; y, por último, los de tipo 1.C $(\mathrm{N}=4)$ ubicados en los sectores $A(n=3)$ y $B(n=1)$ (tabla 1$)$. Las UAC se encuentran casi exclusivamente en el CA1 $(n=7 / N=8)$, mientras que la restante se ubica en el SB y corresponde a una UAC mixta de la Modalidad II.a. De las siete UAC del CA1, tres pertenecen a la Modalidad I (incluyendo una mixta); tres a la Modalidad II.b, y una que combina las Modalidades I y II.a. Esta última es la única que incluye tres recintos (todos del tipo 1.A.m) y en la cual se combinan ambas modalidades.

Morfología y dimensiones de las plantas

Las plantas de los recintos tipo 1.A y 1.C son exclusivamente ortogonales, con formas cuadrangulares, cuadradas y rectangulares, con predominio de estas últimas (figura 7.A). Por otro lado, los recintos tipo 1.B pueden incluir también muros curvos o levemente curvados en las esquinas, lo que genera morfologías más variadas que incluyen plantas circulares, subcirculares, cuadrangulares, subcuadrangulares y semicircular.

Las dimensiones internas de los recintos, mínimas y máximas, según la modalidad de techado, se muestran en la figura 7.B. Ahora bien, si en lugar de considerar los recintos como espacios independientes consideramos a las UA completas, las dimensiones registradas (sin considerar a 
la iglesia de AN1) son: largo mínimo y máximo: 2,76 m y 12,55 m respectivamente (promedio de 5,6 m); ancho mínimo y máximo: 1,55 m y 4,75 m, respectivamente (promedio de 2,9 m).

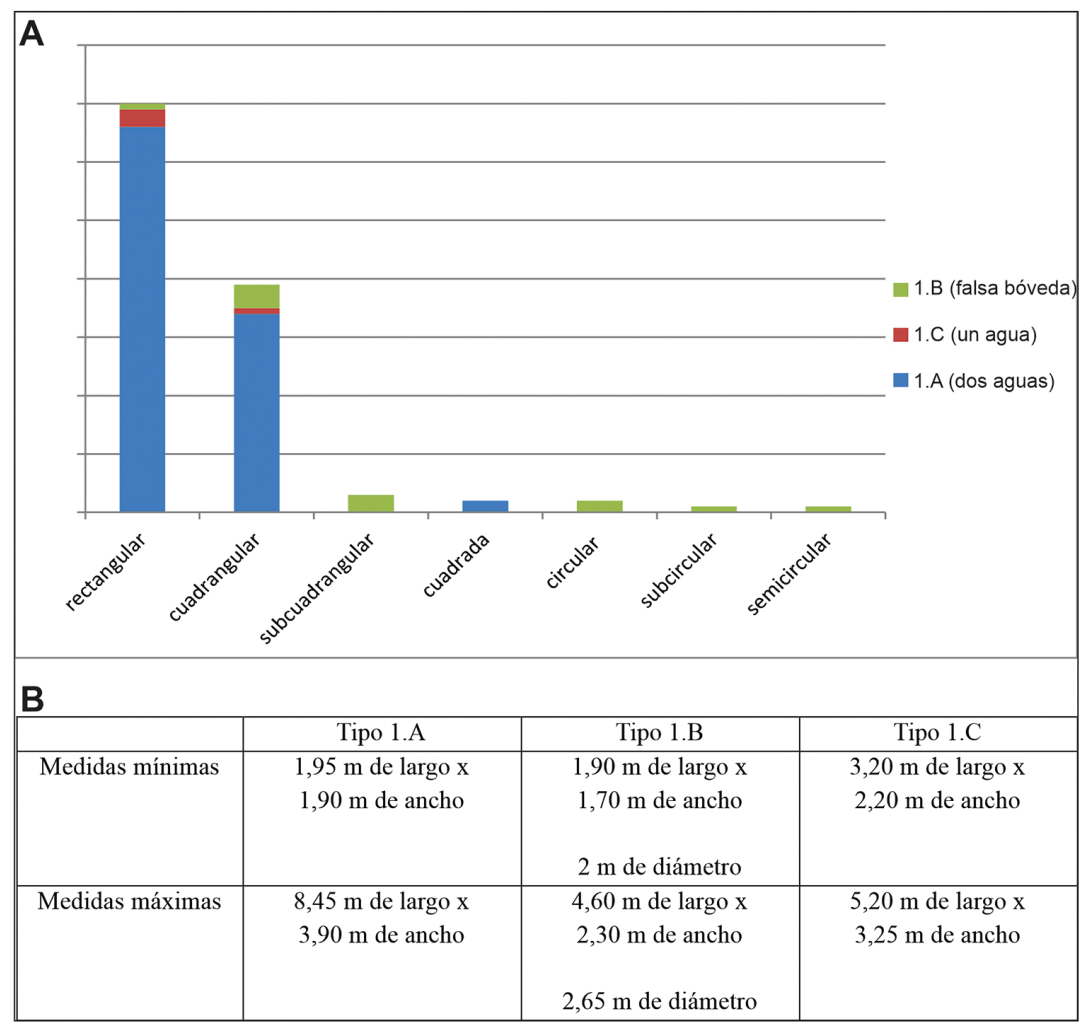

Figura 7. A: Proporciones de las morfologías de plantas de los recintos cubiertos. B: Dimensiones mínimas y máximas de los tipos de recintos según su modalidad de techado. Fuente: elaboración del autor

Las dimensiones de los recintos que estuvieron techados determinan superficies internas que se encuentran entre $3,14 \mathrm{~m}^{2}$ y $32,95 \mathrm{~m}^{2}$. Con el propósito de profundizar en los aspectos dimensionales, determinar si existen relaciones con el tipo de arquitectura y establecer comparaciones entre ambos sitios, se construyeron rangos de superficie con intervalos arbitrarios regulares cada $3 \mathrm{~m}^{2}$ (figura 8). Para la construcción de dichos rangos, las superficies de recintos comunicados entre sí internamente fueron tomadas en conjunto, considerándolos parte de una misma unidad habitacional, por lo que existen casos que superan la medida máxima indicada para los recintos. De ese modo, quedaron conformados doce rangos, de los cuales el último incluye superficies mayores a $34 \mathrm{~m}^{2} .{ }^{5}$ A partir de estas agrupaciones se desprenden conclusiones significativas vinculadas a los tipos de recintos y su distribución según los sitios:

- Los recintos del subtipo 1.A.r se encuentran en todos los rangos de superficie, con excepción del más alto. Su mayor frecuencia se da entre los rangos 3 y 6 (7 a 18,99 m²), con cantidades descendentes en ese orden, pero con proporciones similares en AN y entre los rangos 3-4 y 5-6 en QM4.

- La gran mayoría de los recintos del tipo 1.B (casi el 85\%) se ubica en los dos rangos inferiores.

- En AN1 no se construyeron recintos tipo 1 con superficies correspondientes a los rangos más bajos. 
- En QM4 no hay recintos tipo 1 en el rango 7 o superiores que se encuentren por fuera del CA1. Es decir, que los recintos de los CA2 y 3 (SA) y aquellos de los sectores B, C y D presentan todos superficies menores a $19 \mathrm{~m}^{2}$.

- Entre los rangos 1 y 4 (hasta 12,99 $\mathrm{m}^{2}$ ) las proporciones de recintos son superiores en QM4, o similares entre ambos sitios. Entre el rango 5 y el 11 las mayores proporciones corresponden a AN.

- Los rangos 7, 8 y 9 incluyen solo recintos del subtipo 1.A.r que se ubican en AN1 o en el CA1 de QM4.

- Los únicos espacios que superan los $34 \mathrm{~m}^{2}$ de superficie total cubierta son las UA del subtipo 1.A.m del CA1 de QM4 y la iglesia de AN1.

- Si consideramos el promedio de las superficies totales de las UA (estén comunicadas internamente o no) de cada sector, éstos se distribuyen jerárquicamente de la siguiente manera: 1) QM4-SA: 20,4 m²; 2) AN1: $17 \mathrm{~m}^{2}$; 3) AN7: 11,6 m²; 4) AN4: 10,7 m²; 5) QM4-SB: 8,5 m²; 6) QM4-SD: 5,6 m²; y 7) QM4-SC: 3,3 $\mathrm{m}^{2}$.

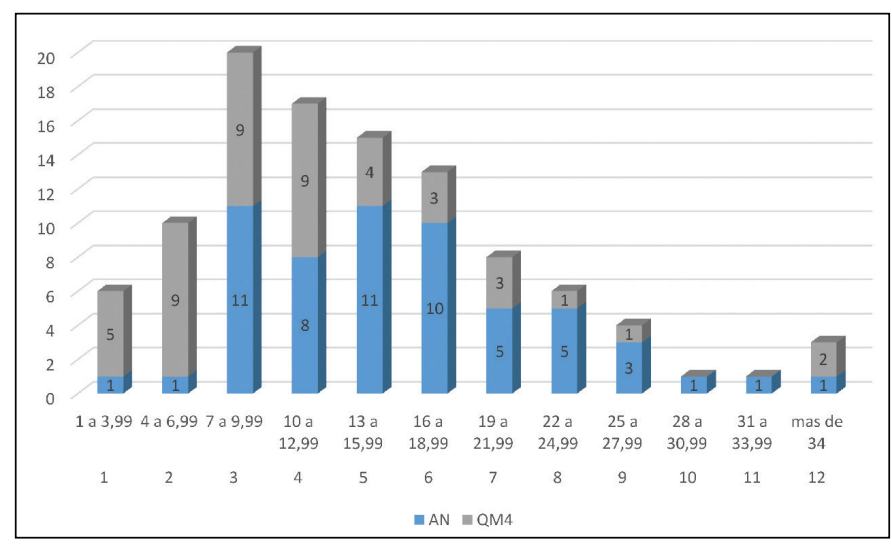

Figura 8. Superficies de recintos techados de ambos sitios agrupadas según rangos regulares. Las medidas inferiores están expresadas en $\mathrm{m}^{2}$. Fuente: elaboración del autor

Rasgos arquitectónicos

Como señalamos antes, se registraron rasgos arquitectónicos correspondientes a vanos (aberturas en los muros que pueden corresponder a puertas o ventanas), nichos (espacios en los muros), poyos (estructuras sobreelevadas de piedra y tierra), muros internos "tipo mesa" (se elevan a media altura), estantes y otros elementos empotrados en los muros.

En construcciones de tipo 1.A los vanos de puertas que comunican al exterior se ubican con mayor frecuencia en uno de los muros sin hastiales (que por lo general son los más largos), mientras que son escasos $(n=5)$ los vanos orientados hacia afuera ubicados en muros con hastiales (muros cortos). El estado de conservación permitió registrar el ancho en 57 casos de AN y 28 de QM4. En el primer sitio esta medida oscila entre $0,4 \mathrm{~m}$ y $1,62 \mathrm{~m}$, con una moda de $0,80 \mathrm{~m}$ y un promedio de 0,81 m. En los recintos tipo 1.A de QM4 es de entre 0,65 m y 1,25 m, con un promedio de 0,86 $\mathrm{m}$ y modas en $0,75 \mathrm{~m}$ y $0,85 \mathrm{~m}$ (figura 9.A). En los recintos de tipo $1 . \mathrm{B}$ varían entre 0,40 y 0,70 $\mathrm{m}$ (promedio y moda de $0,55 \mathrm{~m}$ ), mientras que en aquellos de tipo1.C oscilan entre $0,55 \mathrm{~m}$ y 0,70 $\mathrm{m}$ (promedio de 0,65 m y moda de 0,70 m). En ambos sitios se registraron vanos con derrame, es decir que presentan los lados oblicuos ( $n=31$ en AN y n=20 en QM4). La amplia mayoría se ensancha hacia el interior, con lo cual posiblemente se buscaba un mayor aprovechamiento de la luminosidad natural (figura 9.B). Solo en dos casos, uno en cada sitio, la abertura se reduce hacia 
el interior. Para las alturas de los vanos contamos con menos datos ya que son pocos los casos en los que se conservaron in situ los dinteles de piedra (figura 9.C). En AN son ocho casos, cuyas alturas varían entre 1,35 m y 1,66 m. En QM4 son nueve casos con alturas entre 1,35 m y 1,75 $\mathrm{m}$ en recintos tipo 1.A $(\mathrm{n}=4) ; 1,05 \mathrm{~m}$ y $1,50 \mathrm{~m}$ en recintos tipo $1 . \mathrm{C}(\mathrm{n}=2)$ y $0,85 \mathrm{~m}$ a $1,40 \mathrm{~m}$ en recintos tipo 1.B ( $\mathrm{n}=3)$. Los cerramientos no se conservaron, pero en el testamento de F. Dávalos se indica que algunos estaban hechos con madera de cardón (Trichocereus pasacana) y otros con cuero, e incluían armellas y candado de hierro. ${ }^{6}$
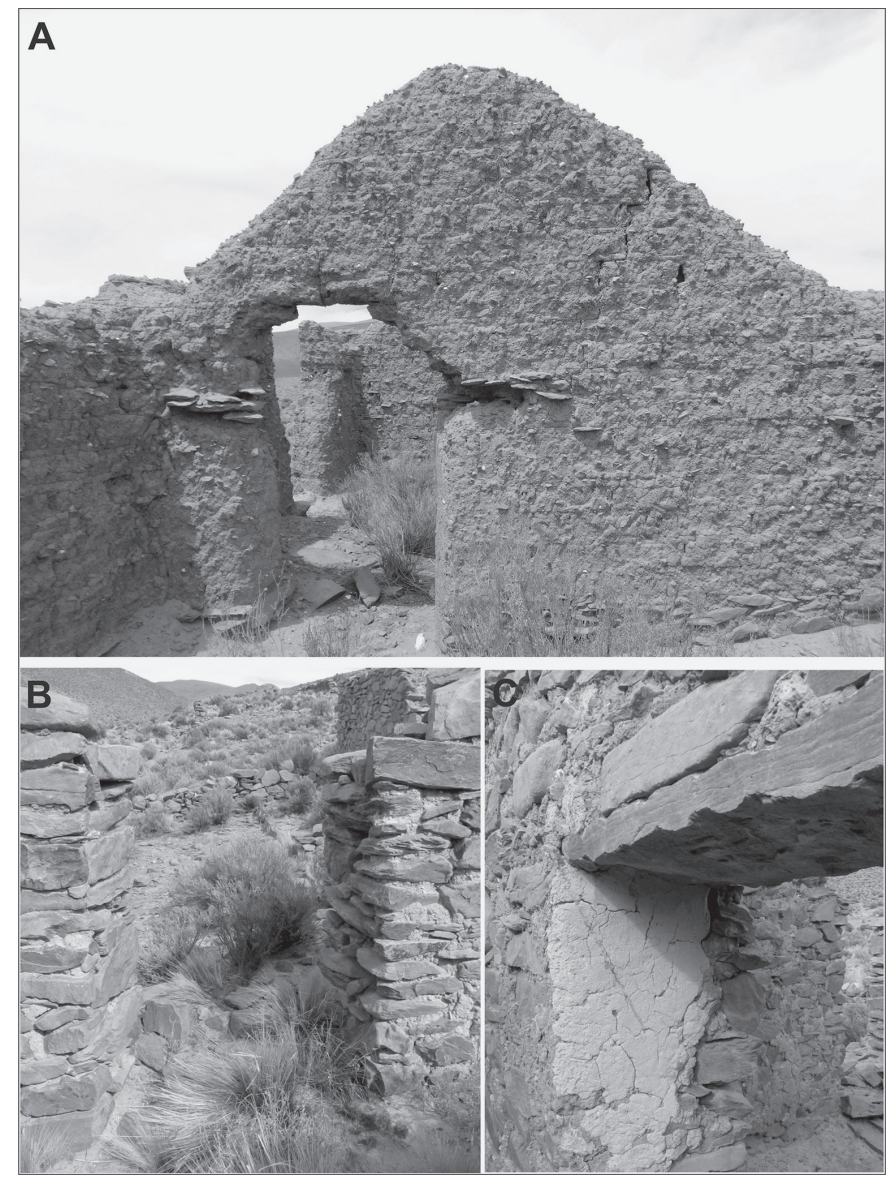

Figura 9. Ejemplos de vanos de acceso conservados. A: Vano en muro de adobe, sin el dintel conservado. B: Muro de piedra con derrame interior (vista desde el interior del recinto hacia el exterior). C: Detalle de dintel de piedra decorado. Fuente: elaboración del autor

Los vanos de ventana no representan un rasgo demasiado frecuente. Se encuentran casi exclusivamente en recintos tipo 1.A, y un único caso en un recinto que correspondería al tipo 1.C. Las más comunes son aberturas cuadrangulares de $0,40 \mathrm{~m}$ a $0,50 \mathrm{~m}$ de lado, con su alféizar a media altura (figura 10.A). En algunos casos sus laterales presentan derrame interior, al igual que lo observado en las puertas (figura 10.B). Una variante está representada por aberturas altas ubicadas en los hastiales, la mayoría de las cuales son más pequeñas (alrededor de 0,20 m de lado) (figura 10.C). Todos los dinteles conservados son de piedra, salvo un único caso en el que fue resuelto en parte con madera de cardón (figura 10.D). 
En AN se registraron veintidós vanos de ventana, distribuidos en una baja proporción de recintos $(\mathrm{N}=18 ; 26,4 \%$ de los recintos tipo 1$)$. La mayor frecuencia se da en aquellos que forman parte de UAC $(\mathrm{n}=11 ; 61,1 \%)$. Esto invierte lo que se observa para la generalidad de los casos y convierte a las ventanas en un rasgo usual en UAC, ya que están presentes en once de las quince construcciones de este tipo (73,3\%). En nueve de estas once, los recintos que poseen ventana/s son los más internos de la unidad, aquellos que no tiene comunicación directa con el exterior. Únicamente en tres recintos se registró más de una ventana, y en todos los casos está relacionado con la presencia de aberturas altas en los hastiales. En QM4 es todavía más baja la proporción de recintos que exhiben ventana: se registraron doce, distribuidos en nueve recintos $(18,3 \%$ de los recintos tipo 1), todos ubicados en el SA (ocho en el CA1 y uno en el CA2). Cuatro de estos recintos corresponden a UAC, dos de los cuales son los más internos de la unidad.

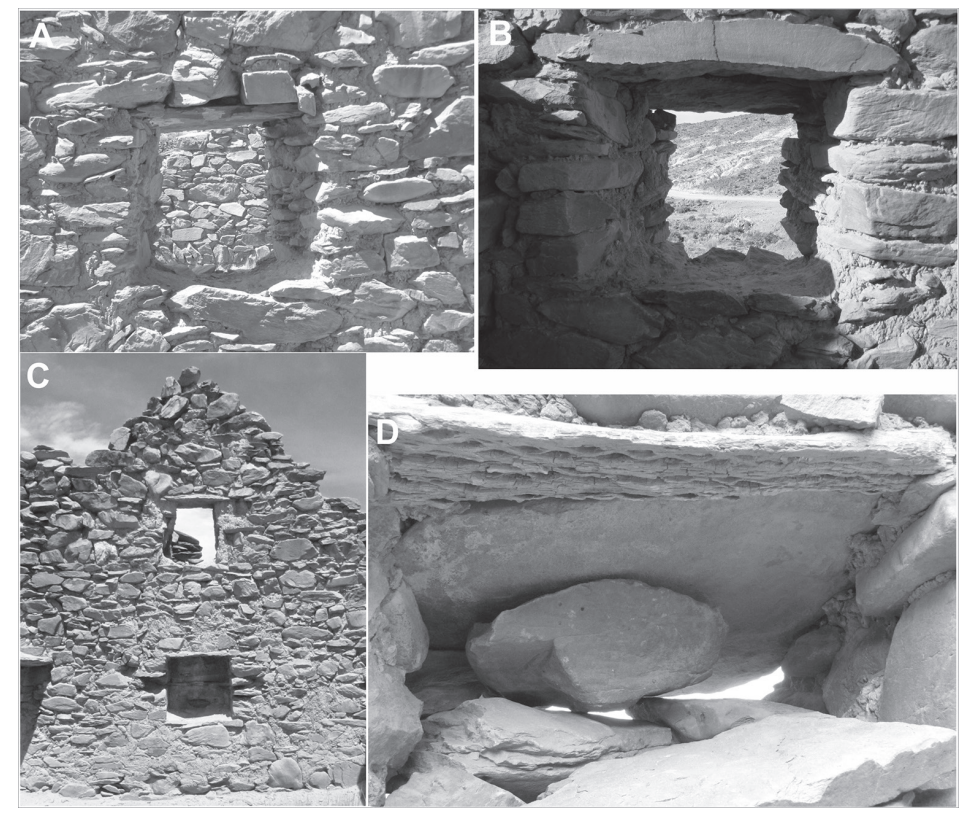

Figura 10. Ejemplos de tipos de vanos de ventana. Fuente: elaboración del autor

Los poyos son estructuras sobreelevadas que se encuentran tanto al interior como al exterior de las construcciones. Para su diferenciación tomamos las denominaciones que propusieron Schilman y Reisner (2011) sobre la base de trabajos etnográficos actuales en Rinconada y Susques (provincia de Jujuy). Los autores distinguen poyos "tipo asiento" y "tipo cama”, señalando que los primeros son por lo general angostos y alargados, mientras que los segundos son más cortos y anchos.

En AN y QM4 la presencia de poyos se restringe a UA que estuvieron techadas y todos los registrados son de piedra y tierra. Los poyos tipo asiento son angostos (máximo 0,40 m) y bajos (máximo 0,30 m), con longitudes variables. En el interior comúnmente están ubicados sobre los muros largos (figura 11.A) y en aquellos que subdividen un espacio, mientras que cuando se presentan en el exterior lo hacen dispuestos contra el muro frontal, por lo general hacia ambos lados del vano de acceso (figuras 11.B y 11.D). Los poyos tipo cama son cuadrangulares o rectangulares, y presentan como medidas mínimas $1,50 \mathrm{~m}$ de largo y $0,80 \mathrm{~m}$ de ancho (figura 11.C). Las alturas registradas van desde $0,15 \mathrm{~m}$ hasta $0,50 \mathrm{~m}$, pero pensamos que las medidas más bajas tienen que ver con la presencia de sedimentación. Si atendemos a su disposición en el interior, la gran 
mayoría se ubica en los muros laterales, por lo general los más cortos, muchas veces ocupando la extensión completa de la pared (figura 11.D).

En AN los poyos tipo asiento ubicados en el interior constituyen un rasgo arquitectónico frecuente. Se presentan en el $67 \%(n=47)$ de los recintos tipo 1. Aquellos ubicados en el exterior presentan una frecuencia menor, que corresponde al 25\% $(n=18)$, y se asocian con mayor frecuencia a UAC. A su vez en este sitio se registraron 55 poyos tipo cama. Están presentes en 42 recintos (61,7\% omitiendo el CA de la iglesia), distribuidos de la siguiente manera: 13 recintos cuentan con dos poyos tipo cama, mientras que en los 29 recintos restantes se ubica un poyo en cada uno. Prácticamente todos los CA $(87 \%)$ cuentan con al menos un recinto que incluye este rasgo. En QM4 solo se registraron 10 poyos tipo asiento, ubicados en 9 recintos $(18,3 \%$; 8 del tipo 1.A y 1 del tipo 1.C), 5 del SA y 4 del SB. También es considerablemente menor la frecuencia de poyos tipo cama, en comparación con AN: se registraron 17, los cuales se presentan en 16 de los recintos techados $(32,6 \%)$. Los espacios que contienen este tipo de poyos están distribuidos de la siguiente manera: 8 en el SA, 7 en el B y 1 en el D. Únicamente en dos UA están presentes de a pares, ambas del SA. Con respecto a los recintos tipo 1.B, solo en 2 de ellos se registró la presencia de un poyo tipo cama, uno ubicado en el SB y otro en el D.

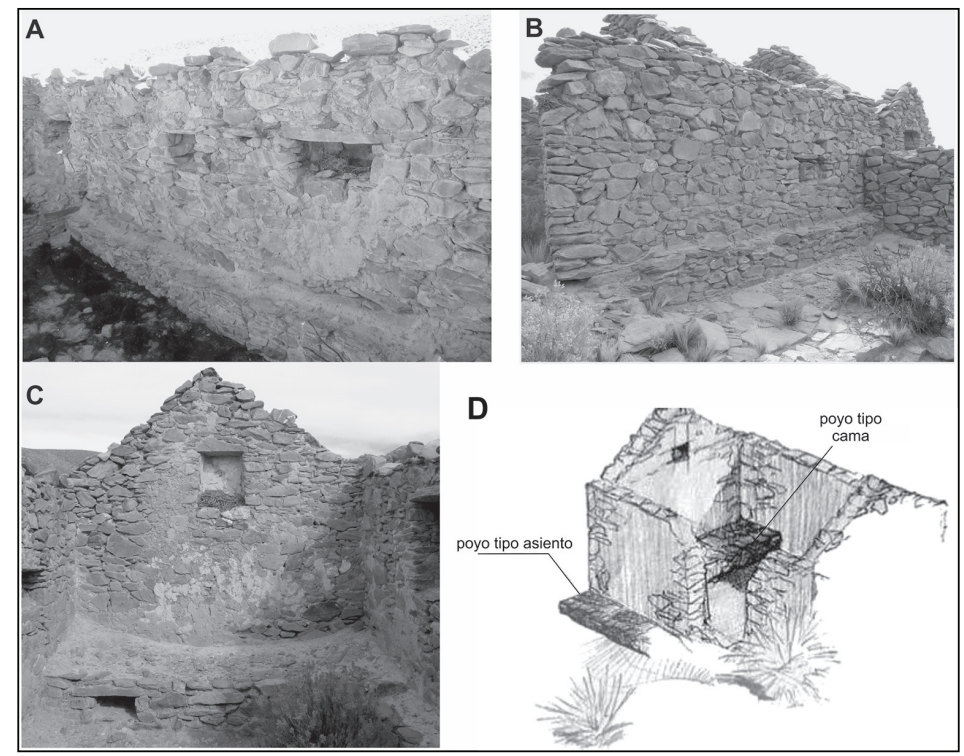

Figura 11. Tipos de poyos registrados. A: Poyo tipo asiento interno. B: Poyo tipo asiento externo. C: Poyo tipo cama. D. Croquis con distribución de poyos en un recinto. Fuente: figuras A, B y C: archivo del equipo Arqueología y Etnohistoria de la Puna Norte; D: Tomada y modificada de Schilman y Reisner (2011:69)

Los muros "tipo mesa" son paredes internas rectangulares (entre 0,45 m y 0,55 m de ancho, y $1,5 \mathrm{~m}$ a 2,3 $\mathrm{m}$ de largo), que se elevan a media altura (entre $0,80 \mathrm{~m}$ y $1 \mathrm{~m}$ aproximadamente) con respecto al nivel de la superficie actual. Los hemos llamado de este modo para diferenciarlos de los muros tipo tabique (construidos con el propósito de separar dos recintos). Por el momento la única referencia etnográfica sobre muros similares que encontramos fue aportada por Boman ([1908] 1991) para el área de Susques (Puna de Atacama, Jujuy), quien señaló que se utilizaba para separar un espacio destinado a conservar alimentos; mientras que muros que separaban áreas de almacenaje fueron registrados arqueológicamente en viviendas del norte de Lípez (Bolivia) fechadas en momento hispano-indígena (Nielsen 2001). En AN se registraron once muros tipo 
"mesa", todos en recintos tipo 1 de diferentes UA, correspondientes a ocho CA de AN1. Se encuentran ubicados en recintos que tienen comunicación directa con el exterior, es decir que en los casos en los que están presentes en UAC con subdivisión interna $(n=6)$, se disponen en el recinto más externo. La mayoría ( $n=9 ; 82 \%)$ está adosado a uno de los muros cortos, y por lo general se ubican hacia la mitad del recinto. En QM4 solo dos recintos que estuvieron techados presentan muros de este tipo, ambos ubicados en el CA1.

Los nichos u hornacinas son espacios en los muros que, de acuerdo con distintos trabajos etnográficos, están destinados a apoyar o guardar objetos (Boman [1908] 1991; Carrizo 1935; Schilman y Reisner 2011; entre otros). Constituyen los rasgos arquitectónicos más frecuentes y abundantes en los sitios analizados en este trabajo. Su presencia mayoritaria se da en UA que estuvieron cubiertas, aunque no son exclusivos de éstas, ni siquiera únicamente de construcciones habitacionales. ${ }^{7}$ En la gran mayoría de los casos están conformados con piedra, y solamente hemos registrado dos en los que se utilizó madera. Las medidas más frecuentes se ubican entre 0,30 m a 0,40 $\mathrm{m}$ de base; $0,25 \mathrm{~m}$ a 0,40 $\mathrm{m}$ de altura, y $0,25 \mathrm{~m}$ a $0,35 \mathrm{~m}$ de profundidad. Presentan forma cuadrangular o trapezoidal (figura 12), exceptuando un nicho resuelto en falso arco en un recinto del CA12 de AN1. Algunos contienen estantes intermedios generando compartimientos dobles o triples (figuras 12.C, 12.D y 12.E), aunque son menos frecuentes.

En AN hemos contabilizado 139 nichos, de los cuales 12 son dobles. Están presentes en 60 recintos de tipo 1 (88\%) y en prácticamente todos los CA, con un promedio de 2 nichos por recinto. En este aspecto destaca por inusual el recinto 2 (R2) de CA11, con 14 nichos. En QM4 hemos registrado 73 nichos, presentes en 32 recintos: 15 del SA; 12 del B y 5 del D. En los espacios que estuvieron techados están presentes en el $59 \%$ de los casos $(n=29)$, en recintos con los tres tipos de cubierta.

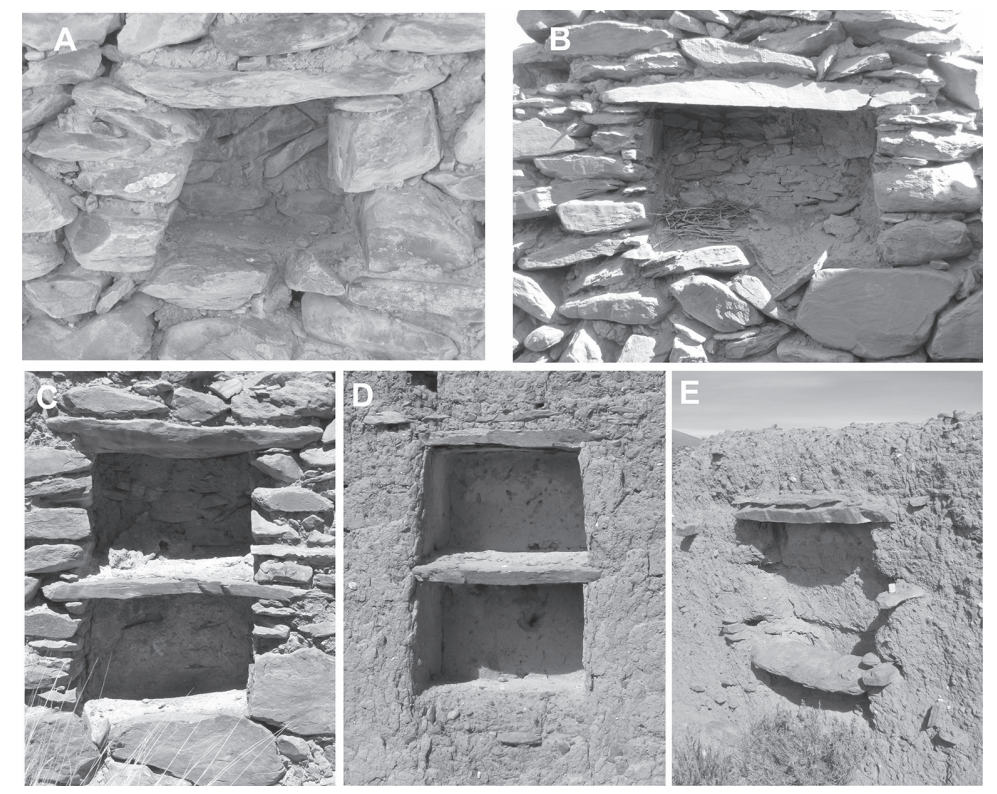

Figura 12. Ejemplos de tipos de nichos registrados. Fuente: elaboración del autor

Los estantes o repisas se confeccionaron en su gran mayoría con rocas planas tipo lajas que sobresalen entre 0,20 a $0,30 \mathrm{~m}$, empotradas en los muros internos por lo general a alturas similares que los nichos. En AN esta clase de rasgo se presenta de manera bastante frecuente: al menos un estante en 88 muros correspondientes a 49 recintos (72\%). En QM4 su presencia 
es más limitada: se registraron en 19 muros de 14 recintos $(28,6 \%)$, la mitad del SA y la otra del SB. A su vez, hemos registrado otros elementos empotrados, que se presentan con menor frecuencia que los rasgos anteriores: cuernos de fauna europea (Bos Taurus), rocas prismáticas y madera. Los fragmentos de maderas se ubican alineados, por lo que podrían haber constituido el soporte de estantes, mientras que los otros elementos tal vez estuvieron destinados a colgar objetos.

Sintetizando la presencia de rasgos arquitectónicos desde un aspecto cuantitativo, éstos son notoriamente más frecuentes en AN que en QM4 (figura 13). En este sentido, la gran mayoría de las construcciones de AN presenta un arreglo o equipamiento caracterizado por la presencia de elementos fijos destinados a cubrir necesidades de uso interno. En QM4 solo son comparables con AN los recintos ubicados en el SA y algunos correspondientes al SB.

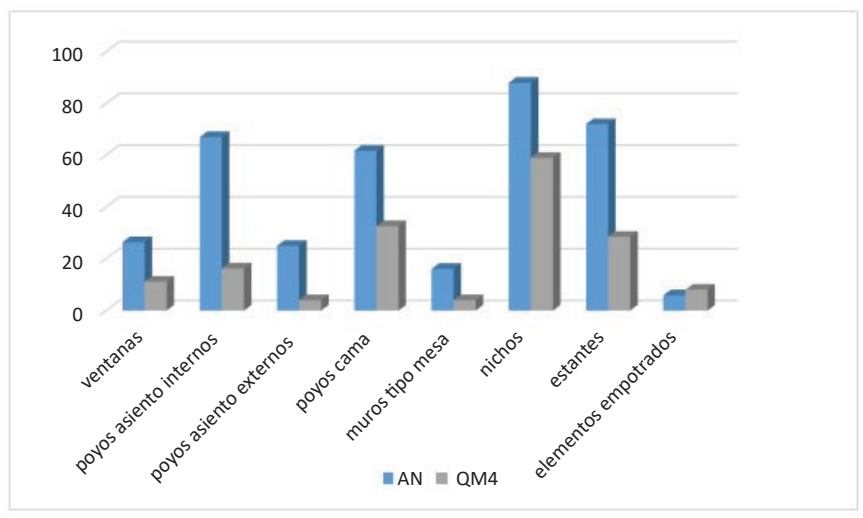

Figura 13. Frecuencia porcentual de rasgos arquitectónicos en recintos techados de ambos sitios. Fuente: elaboración del autor

\section{Recintos tipo 2 (no techados)}

La determinación de recintos que no habrían estado cubiertos estuvo basada en la combinación de características constructivas, mediante la constatación de atributos ausentes y/o presentes. Los primeros tienen que ver con la ausencia de hastiales, de diferencias de altura entre dos muros paralelos que permitan pensar en un techado con caída única, o de hiladas superiores desaplomadas que sugieran un techo en falsa bóveda. Otro indicio sería la ausencia de rocas de derrumbes en las proximidades que justifiquen la inexistencia de hastiales o techos de piedra. Por otro lado, atributos positivos tienen que ver, principalmente, con muros en "pirca seca" (ausencia de argamasa o mortero), baja o media altura, amplias superficies y aberturas bajas en los muros. En el primer caso se trata de un aspecto constructivo que, si bien no impide la colocación de un techo, dificultaría la posibilidad de los muros de soportar una techumbre ya que las rocas por lo general se dispusieron sin buscar una trabazón completa entre ellas que les otorgue firmeza estructural ante la ausencia de un componente aglutinante. Algunos sí presentan argamasa, pero solo en hiladas inferiores. Además, muros de altura baja actual y sin evidencias significativas de derrumbes podrían estar señalando recintos que no se construyeron con el propósito de ser cubiertos. Con respecto a las superficies, pensamos que es improbable (o poco habitual) que se hayan techado espacios demasiado amplios ya que se requeriría de componentes constructivos adicionales, como postes de madera provenientes de especies arbóreas cuya disponibilidad es escasa en el área de estudio. Por último, aberturas que se registraron ubicadas al ras de la superficie habrían estado 
destinadas al drenaje de agua de lluvia y con ello evitar el anegamiento de los espacios y/o la presión del agua sobre las paredes.

Sobre la base de estas consideraciones determinamos la presencia de 60 recintos que no habrían estado cubiertos: 29 en AN y 31 en QM4.

\section{Componentes y elementos constructivos}

En este tipo de recintos solo se registró el uso de piedra como componente constructivo principal. El uso de argamasa, cuando se observa su presencia, en la mayoría de los casos se limita a los sectores inferiores de los muros. Éstos presentan alturas que por lo general se ubican entre 0,20 m y 1,65 m (es decir, baja a media). La técnica de construcción es similar a la empleada para la construcción de recintos techados, en el sentido de que se disponen bloques a doble hilera, salvo que en algunas ocasiones se utilizaron rocas más grandes para levantar muros de hasta 0,80 $\mathrm{m}$ de ancho. En todos los casos se trata de aparejos rústicos, en algunos con rocas dispuestas de manera oblicua.

\section{Modalidades constructivas}

Es posible hacer una primera distinción de los recintos considerando si se trata de unidades arquitectónicas o no. Por un lado, existen espacios donde la mayor parte de los límites está dada por muros con continuidad estructural e interrupciones solo para vanos de acceso, por lo que podemos interpretar que corresponden a una única voluntad constructiva. En cambio, los recintos que no pueden ser considerados UA están delimitados por muros que no presentan continuidad constructiva entre sí, o incluso corresponden a otras construcciones. En este sentido, es posible interpretar que se conformaron como recintos luego de reiteradas adiciones de elementos constructivos.

Cuando se trata de UA, éstas son de tipo simple o compuesta. Las compuestas mixtas ya fueron tratadas al analizar los recintos techados, mientras que aquellas que incluyen dos recintos tipo 2 están conformadas por un muro perimetral amplio cuyo interior presenta un muro interno que se adosa a parte de las paredes externas generando dos espacios (Modalidad III). En la mayoría de los casos, se construyó un recinto pequeño en el interior. Se han registrado cuatro UA de esta modalidad, tres en AN1 y una en AN4.

Morfología y dimensiones de las plantas

Estos recintos presentan una gran variabilidad en las formas y superficie de las plantas, por lo que consideramos conveniente analizar estas características en función de agrupaciones que contemplen las modalidades que hemos señalado antes y la manera en que se disponen espacialmente.

En primer lugar, como hemos indicado, existen recintos $(n=14)$ en los cuales una parte de los límites está dada por muros correspondientes a otros recintos, principalmente de tipo 1, y otra se completa mediante el agregado de muros adosados a dichas construcciones (figura 14.A). En este sentido, debido a que la totalidad o gran parte de sus contornos está dada por varios elementos arquitectónicos que no presentan continuidad estructural o trabazón entre ellos, no podemos clasificarlos estrictamente como UA. Por lo general, ocupan un espacio central dentro de los CA, intermediando entre el espacio exterior y recintos tipo 1. Los hemos denominado de manera genérica como "patios" (tipo 2.A), con la pretensión de sintetizar características morfológico-arquitectónicas y de disposición espacial, antes que funcionales. Incluyen superficies que van desde $6,9 \mathrm{~m}^{2}$ hasta $1.180 \mathrm{~m}^{2}$ y están delimitados por muros rectos que dan lugar a plantas 
rectangulares $(n=5)$, cuadrangulares $(n=2)$, poligonales o irregulares $(n=6), y$ un caso con parte del límite conformado por un muro curvo, que presenta una planta en cuadrante (un cuarto de círculo). Las dos últimas morfologías se relacionan con construcciones que se ajustan a la ubicación de recintos preexistentes. La mitad de los recintos descriptos se ubican en el SA de QM4. Entre éstos, la mayoría corresponde a los espacios ubicados en el interior del CA1. De los siete restantes, cinco se distribuyen entre los SB y D de QM4, y dos en AN1. Los espacios de mayores superficies son aquellos ubicados en el SA de QM4 y en AN1 (todos mayores a $50 \mathrm{~m}^{2}$ ); en cambio los que se disponen en los SB y D son menores a $32 \mathrm{~m}^{2}$.

Por otra parte, identificamos recintos, en su mayoría correspondientes a UAS, que comparten ciertos atributos arquitectónicos y espaciales por los cuales merecen ser considerados en conjunto (tipo 2.B). Se trata de construcciones que se encuentran de manera adyacente y estrechamente vinculadas a recintos techados, ya sea adosadas, muy próximas, o conformando con éstos UAC mixtas (figura 14.B). En el $92 \%$ de los casos ( $\mathrm{n}=23 / \mathrm{N}=25$ ), las superficies se ubican entre $2 \mathrm{~m}^{2}$ y $17 \mathrm{~m}^{2}$. Con respecto a la morfología, predominan las plantas ortogonales: 18 (72\%) son rectangulares o cuadrangulares; 5 son subcirculares y los restantes corresponden a un recinto semicircular y otro de forma cuadrante.

En tercer lugar, registramos tres recintos correspondientes a UAS de superficies muy reducidas $\left(1,8\right.$ a $\left.3,8 \mathrm{~m}^{2}\right)$, constructivamente similares a los anteriores, pero que se encuentran aislados (tipo 2.C), es decir, sin asociación directa con otros espacios construidos (figura 14.C). Dos de ellos presentan planta cuadrangular y uno, subcircular.

Por último, agrupamos dentro del tipo 2.D a dieciocho recintos cuyos muros perimetrales delimitan espacios de "amplia superficie" (entre 23 y $625 \mathrm{~m}^{2}$ ) (figura 14.D). Conforman catorce UA, ya sea simples (10 recintos) o compuestas (4 UAC con dos recintos cada una). En todos los casos son UA, pero no siempre integran CA junto a otro tipo de recintos, sino que en algunos casos se presentan como las únicas construcciones de un conjunto o incluso como recintos aislados. Los recintos que conforman UAC corresponden a la Modalidad III, es decir que se presentan de a pares: están conformadas por muros perimetrales externos y uno interno que separa ambos espacios. Considerando las morfologías según los límites externos de las unidades arquitectónicas, éstas presentan plantas rectangulares y cuadrangulares $(n=5)$, cuadradas $(n=2)$, subcirculares $(\mathrm{n}=6)$ y semicircular $(\mathrm{n}=1)$.

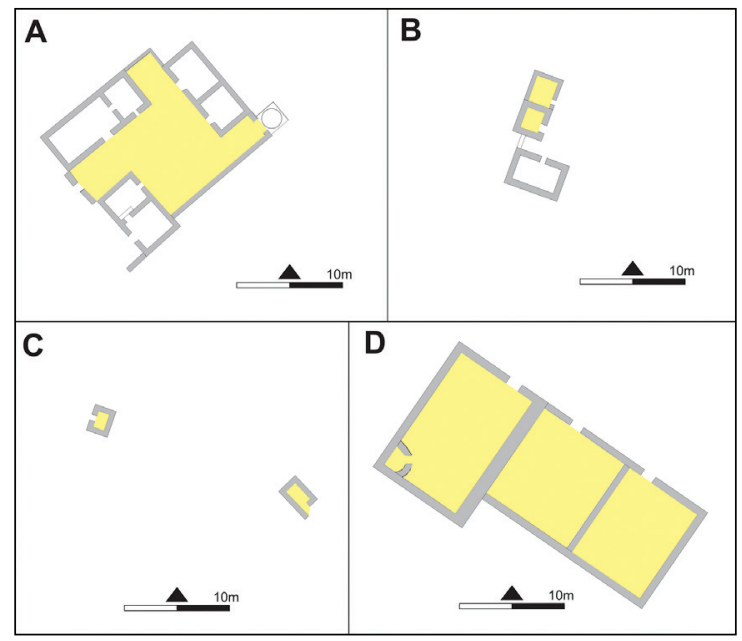

Figura 14. Planos en los que se representa con superficies sombreadas distintos tipos de espacios que no estuvieron cubiertos. A: Recinto tipo 2.A ("patio"); B: Recintos tipo 2.B ("adyacentes"); C: Recintos tipo 2.C ("aislados"); D. Recintos tipo 2.D (“de amplia superficie"). Fuente: elaboración del autor 
Rasgos arquitectónicos

Este tipo de recintos presenta rasgos arquitectónicos que, por lo general, se limitan a vanos de ingreso y aberturas en la base de los muros, aunque también existen unos pocos casos en los que se registraron nichos, estante de laja, cuerno empotrado y un posible muro tipo mesa. El ancho de los vanos se pudo registrar en 23 de los 60 recintos, y oscila entre 0,40 m y 1,45 m. Por lo general, los vanos mayores a $0,70 \mathrm{~m}$ de ancho corresponden a recintos de tipo 2.D. En dos recintos de AN1 los vanos de ingreso presentan derrame interior, lo cual es llamativo tratándose de espacios descubiertos. Algunos presentan una o dos aberturas cuadrangulares en la base de los muros, que habrían funcionado como desagües, mientras que se registraron solo dos recintos que presentan un nicho cada uno.

\section{Espacios Anexos}

Estos espacios están delimitados de manera parcial, por lo general mediante la construcción de muros de hasta 1,20 m de altura adosados o muy próximos a recintos, cuyos muros también participan en la delimitación. Dentro de los anexos identificamos, por un lado, construcciones de un único muro adosado o próximo que genera un espacio más bien reducido, a las cuales denominamos anexos tipo 1 (figura 15.A). En total registramos 26 espacios de este tipo: 19 en AN, distribuidos en 10 CA (9 de AN1, y 1 en AN4); y 7 en QM4, ubicados en 5 CA (uno del SA y cuatro del SB) (tabla 1). Por otro lado, cuando se involucra más de un muro se genera una circunscripción algo mayor que en los casos anteriores, lo que crea volúmenes con superficies relativas más amplias. A estos espacios los denominamos anexos tipo 2 (figura 15.B), y fueron registrados en 14 casos: 9 en AN, distribuidos en 8 CA (7 de AN1 y 1 de AN7); y 5 en QM4, distribuidos 1 en un CA diferente, correspondientes a los sectores $\mathrm{A}(\mathrm{n}=1), \mathrm{B}(\mathrm{n}=2)$ y $\mathrm{D}(\mathrm{n}=2)($ tabla 1$)$.

Ninguno de los dos casos presenta rasgos arquitectónicos, pero algunos del segundo tipo, al tratarse de espacios más amplios, incluyen otras construcciones en el interior, como por ejemplo un horno $(\mathrm{H})$.

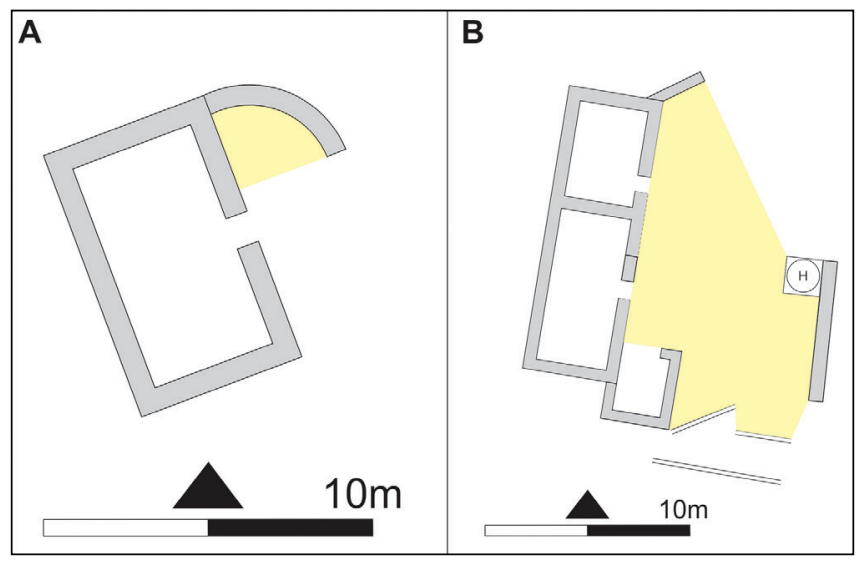

Figura 15. Ejemplos de espacios anexos (sombreados). A: anexo tipo 1. B: anexo tipo 2. Fuente: elaboración del autor 


\section{Hornos y "huesero"}

No queremos dejar de mencionar estructuras que, si bien no constituyen espacios construidos, están asociadas a la arquitectura y consideramos relevantes para interpretar los modos de habitar y la posible funcionalidad de algunos espacios. En primer lugar, se registraron restos de hornos o sus bases, las cuales fueron construidas con piedra y argamasa en dimensiones bastante regulares que rondan los $2 \mathrm{~m}$ de lado, entre 1,80 m y 2,20 m. Aunque ningún horno se conservó de manera completa, los que presentan mayor integridad permitieron distinguir que se trataba de hornos de piedra (figura 16.A). Como hemos señalado, en otros casos solo se conservaron sus bases, sobre las cuales en algunos casos hay restos de rocas y en otros, sedimento acumulado, lo que sugeriría no descartar la construcción de hornos en adobe.

En AN se registraron diez hornos y/o los restos de sus bases, todos ubicados en CA diferentes (nueve en AN1 -figura 16.A- y uno en AN4) y dispuestos en los sectores externos inmediatos a las UA. En QM4 solo hemos registrado dos estructuras que corresponderían a hornos de tipo doméstico, una de las cuales se encuentra en el CA1 asociada a las UA de adobe y la segunda en el SB. Postulamos que fueron utilizados para tareas como elaborar pan o cocinar carne, ya que no registramos características que hagan presumir su uso para fundición metalúrgica (vitrificación en paredes y pisos internos, presencia de escoria metalúrgica, ceniza en el interior, entre otras), como sí se han detectado en hornos de tipo reverbero en otros sitios coloniales de la Puna de Jujuy (cfr. Becerra 2014a; Angiorama y Becerra 2017).

Por otra parte, en una de las esquinas internas de Patio 2 del CA1 de QM4 se ubica una estructura cilíndrica de $4 \mathrm{~m}$ de diámetro con muros de piedra (figura 16.B). En su interior se registró una gran cantidad de restos óseos de fauna, algunos de los cuales exhiben signos de termoalteración, lo cual indicaría que se trata de una estructura destinada al descarte y quema de huesos ("huesero").

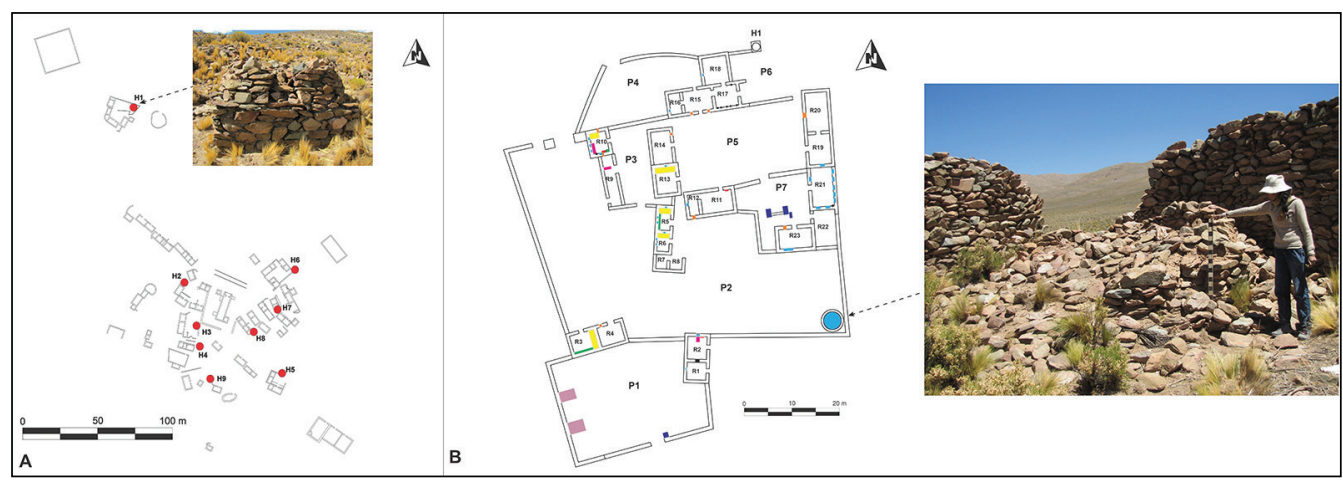

Figura 16. Estructuras de combustión registradas. A: Distribución de los hornos y/o bases en AN1 y detalle del horno (H1); B: Ubicación y detalle del "huesero" en Patio 2 del CA1 de QM4.

Fuente: elaboración del autor

\section{DISCUSIÓN}

Los resultados permitieron aproximarnos a las modalidades constructivas, arribar a interpretaciones funcionales y generar propuestas acerca de la configuración de los sitios y los modos de habitar. A continuación, retomaremos estos ítems, en articulación con datos provenientes de nuestros análisis de fuentes escritas, de estudios etnográficos y de investigaciones arqueológicas de otros sitios. 


\section{Aspectos técnico-constructivos}

Con respecto a los componentes constructivos, destaca el uso extendido de la piedra, mientras que la utilización del adobe estuvo restringida a escasas construcciones. Incluso en estas últimas, las rocas locales formaron parte fundamental de la arquitectura como sobrecimiento e integrando rasgos como estantes de nichos o dinteles. En este sentido, el adobe parece haber sido un material de uso bastante limitado durante la etapa de control europeo, tanto en Antiguyoc como en otras localidades de la Puna de Jujuy. ${ }^{8}$ El empleo de madera se registró en unos pocos rasgos arquitectónicos, cerramientos de algunas puertas y seguramente para la confección de techos a una y dos aguas.

Dentro de los espacios cubiertos, es decir, aquellos que habrían constituido el ámbito básico y central de la vivienda, las construcciones más comunes son UAS de planta rectangular o cuadrangular y muros de piedra que estuvieron techadas a dos aguas. Sin embargo, en el CA1 de QM4 y en ciertos CA de AN1 se observa la presencia de algunas UAC, para las cuales hemos reconocido diferentes modalidades constructivas. Por lo general, son edificaciones que estuvieron destinadas a contener dos recintos, lo cual se logró subdividiendo un espacio original, o bien creando dos espacios desde el momento mismo de la construcción. Si bien no parece haber sido un aspecto determinante, la mayoría de aquellas cuyo largo supera los $7 \mathrm{~m}$ se dividió utilizando un muro con hastial, mientras que la mayor parte de las que presenta una longitud inferior a la señalada se segmentó mediante muros tipo tabique.

Los muros se ejecutaron con una técnica que revela cierta uniformidad y se lograron aparejos similares, en su mayoría de tipo rústico. Una variante, aunque más restringida, consistió en disponer rocas de manera oblicua en parte de los lienzos. La aplicación más notoria de este recurso se dio con la técnica de espina de pez. La techumbre, a juzgar por referencias existentes en fuentes coloniales de áreas próximas (Lizárraga [1605] 1999; Cobo [1653] 1964; Muñoz Ovalle 2014, entre otras) se habría realizado de manera similar a aquellas que exhiben viviendas actuales de tierras altas del espacio andino, es decir mediante "torta de barro" o "guayado" (Delfino 2001; Tomasi 2012).

En una proporción mucho menor se registraron refugios de planta subcircular o subcuadrangular que estuvieron cubiertos con rocas en falsa bóveda. Se trata de espacios de construcción expeditiva y con una superficie reducida. Por último, la menor cantidad de espacios techados está dada por las construcciones en piedra que habrían estado cubiertas a un agua.

Por lo general, todos los recintos cuentan con un único vano de acceso y las comunicaciones internas son escasas, como también lo fueron las modalidades constructivas destinadas a crear espacios demasiado privados o restringidos. Los vanos de acceso a los espacios cubiertos son, usualmente, pequeños y muchas veces se caracterizan por presentar derrame interior. Esta característica también fue registrada en otras estructuras coloniales de la Puna de Jujuy, como el Cabildo de Rinconada, y en instalaciones mineras del siglo XIX de la zona de Capillitas, provincia de Catamarca (Delfino et al. 2014). Consideramos que podría tratarse de un rasgo introducido a partir de la conquista española, si tenemos en cuenta que por el momento no contamos con datos de su registro en sitios prehispánicos, pero sí se documentó en la arquitectura europea al menos desde época medieval (cfr. Sánchez Zufiaurre 2007). Los vanos de ventana presentan una baja frecuencia en UAS, pero sucede lo contrario en UAC, donde se ubican en el recinto más interno. Esto podría indicar, para el caso de aquellas de la Modalidad I, que la división interna ya estaba planificada al momento de la construcción, ya que el vano de puerta se ubica hacia el otro extremo, es decir, ambas aberturas habrían sido distribuidas teniendo en cuenta los recintos proyectados en el interior.

El análisis realizado muestra que más allá de detalles que se observan como singularidad local, existen rasgos generales compartidos con modos de construir y habitar que se registraron o 
describieron para momentos contemporáneos, tanto en la Puna de Jujuy como en otros espacios de los Andes, en particular de sitios con actividades mineras ubicados en sectores altiplánicos (cfr. Cruz et al. 2012; Lema 2012; Angiorama et al. 2018a, 2019; Quisbert et al. 2018; entre otros). La mayor parte de las referencias consultadas indican viviendas por lo general rectangulares, con uno o dos cuartos, techos de paja y barro, estrechos vanos de acceso y en pocos casos ventanas. A su vez, para ciertas localidades se mencionan viviendas circulares y a veces se habla de casas pequeñas similares a "cuevas" u "hornos" (Carrió de la Vandera [1773] 1942:230), lo que podría hacer referencia a refugios con techo de piedra.

Por otro lado, podemos observar que en la localidad de Antiguyoc, la mayoría de las viviendas revela un modo de construir que consiste en la articulación y estandarización de rasgos que están presentes en parte de la arquitectura andina de momentos pre-conquista. Es decir, que en los sitios estudiados gran parte de los modos utilizados para construir las habitaciones durante el período de dominación hispana exhiben una conjunción de elementos que formaron parte de arquitecturas de períodos previos (en especial de aquellos inmediatamente anteriores, esto es, Tardío e Inka), tanto de manera estrictamente local (Puna de Jujuy) como en otros puntos del espacio andino. Dichos elementos tienen que ver principalmente con la presencia de recintos de plantas ortogonales edificados con muros de piedra a hilera doble con argamasa; cubiertas a dos aguas; unidades arquitectónicas de habitación simple; escasa presencia de comunicación interna entre recintos; rasgos como nichos u hornacinas (incluyendo morfologías trapezoidales); poyos y muros internos, entre otros (cfr. Rowe 1946; Gasparini y Margolies 1977; Suetta y Alfaro de Lanzone 1979; Morris 1987; Schávelzon y Magadán 1992; Raffino 1993; Nielsen 2001; Albeck y Ruiz 2003; Raffino et al. 2004; Protzen 2008; Vaquer 2010; entre otros). La continuidad de modalidades constructivas que se registraron para momentos prehispánicos también está presente en técnicas arquitectónicas como el techado en falsa bóveda. Aunque en esa época este tipo de cubierta se habría destinado a estructuras de tipo no-habitacionales (tumbas y/o depósitos), es un rasgo documentado en diversos sitios del área andina (cfr. Gasparini y Margolies 1977; Raffino 1993; De Feo et al. 2007; Cohen 2010; entre otros). En cambio, exceptuando las aberturas con derrame, los detalles arquitectónicos que podrían vincularse a técnicas o estilos europeos son muy escasos y por lo general están restringidos a unos pocos recintos.

\section{Aspectos funcionales}

Si consideramos ambos sitios en conjunto, podemos afirmar que al menos el $67 \%$ de los recintos que se construyeron estuvieron techados, para lo cual se recurrió a diferentes modalidades de cubiertas, entre las cuales predomina el tipo a dos aguas. Exceptuando la iglesia ubicada en AN1, el resto de las construcciones podría haber estado formando parte de espacios de vivienda y/o depósito de elementos. La presencia de un techo permite interpretar que se trata de los espacios en los que se desarrollaron actividades que requieren la protección del frío, viento y lluvia, como dormir y almacenar alimentos u otro tipo de elementos. Tampoco debemos descartar que en algunos de ellos se hayan llevado a cabo actividades de cocina internas. Para ello se dispusieron elementos fijos como poyos tipo cama y tipo asiento, estantes, nichos y muros tipo mesa. Los nichos u hornacinas habrían sido uno de los rasgos arquitectónicos más habituales e importantes para los ocupantes, destinados seguramente a guardar elementos domésticos y quizás también objetos vinculados a prácticas de culto. En algunos casos, el espacio exterior inmediato también fue dotado con rasgos como poyos tipo asiento.

Resulta interesante analizar cómo se presentan rasgos como los muros tipo mesa, los poyos tipo cama y tipo asiento en el interior de las UA. Un aspecto a destacar es que, salvo un caso, los muros tipo mesa no se encuentran en el mismo recinto que los poyos tipo cama. Por lo general, 
en las UAC cuyos recintos presentan una comunicación interna entre sí, se observa una tendencia hacia la siguiente configuración: el recinto más interno, es decir aquel que no se comunica directamente con el exterior, presenta por lo general una superficie menor que el externo. Allí se construía un poyo tipo cama, nichos y, en algunos casos, una ventana. En el espacio más externo se dispusieron poyos tipo asiento, nichos y estantes, y en algunos casos también se construyó un muro tipo "mesa". Esto estaría señalando una segregación espacial de las actividades que se realizaron en el interior, con una habitación interna con menor "permeabilidad" desde el exterior, destinada principalmente al descanso; y otra con un acceso directo desde afuera en el que se dispusieron una serie de elementos fijos destinados al almacenamiento/resguardo de provisiones y objetos. A su vez, este también pudo haber sido un espacio de reunión y consumo de alimentos por parte de los ocupantes de la construcción (figura 17).

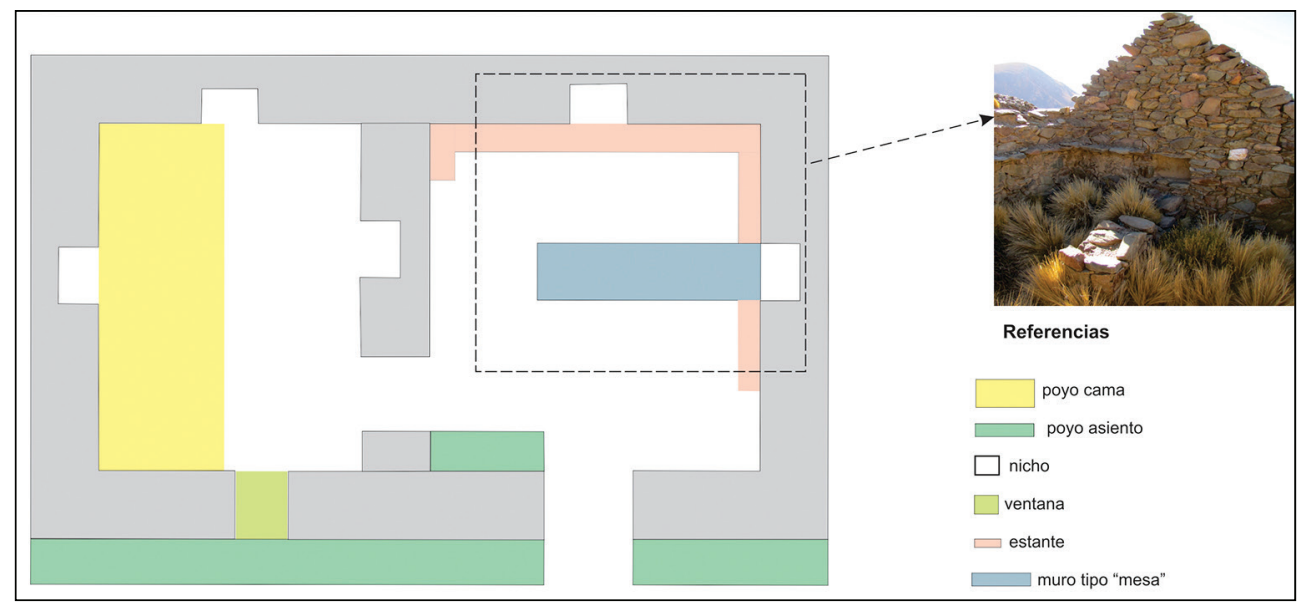

Figura 17. Esquema de planta de una UAC con recintos comunicados y disposición más frecuente de los rasgos arquitectónicos. Fuente: elaboración del autor

Los recintos tipo 1.B se encuentran dentro de los espacios techados de menores superficies. De los nueve CA en los que están presentes, en cinco de ellos se presentan como la única construcción techada de sus respectivos conjuntos. Se trataría de unidades mínimas de vivienda en las que la necesidad de refugio se resolvió de manera expeditiva y sin la necesidad de contar con materiales extras además de piedra, como por ejemplo maderas para el techo. Exceptuando dos casos, al parecer no se construyeron poyos en su interior, pero sí son frecuentes los nichos. Los recintos tipo 1.C también podrían haber funcionado como vivienda, depósito de elementos y/o cocinas techadas, ya que la mitad contiene un poyo tipo cama y la otra mitad, poyo tipo asiento, nichos y estantes.

Sea cual fuera la modalidad de construcción y techado, en la mayoría de los casos este tipo de construcciones se presenta asociada, al menos, con un espacio construido externo descubierto. Los recintos clasificados como 2.A ("patios") por lo general ocupan una posición central en los CA. Salvo los denominados Patio 1 y Patio 2 del CA1 de QM4, el resto podría haber funcionado como espacios para actividades domésticas, en vinculación con los recintos próximos. De igual manera sucede con la mayoría de los anexos tipo 2, aunque en estos casos el perímetro no se delimitó físicamente de manera completa. En otros casos se trata simplemente de delimitaciones parciales hacia el frente de un único recinto. En AN1 únicamente los CA 1 y 8 contaron con patios centrales completamente cerrados. Sin embargo, en el primero, los muros no tienen en la actualidad demasiada altura (hasta $1,10 \mathrm{~m}$ ) y no parecen haberla tenido. En cambio, en el CA8 
existió la intención de aislar los recintos y el horno mediante la construcción de muros de hasta 2,40 m de altura, lo que evita el acceso y la visibilidad desde el exterior. En QM4 esta situación de mayor "aislamiento" o privacidad se da únicamente en el CA1.

Los recintos de tipo 2.B, por lo general, están estrechamente vinculados a los espacios de tipo 1. El $80 \%(n=20 / N=25)$ presenta superficies reducidas, hasta $9 \mathrm{~m}^{2}$. Éstos podrían haber sido utilizados como cocinas externas descubiertas (similares a los actuales fuegueros o canchas de asentamientos pastoriles; cfr. Göbel 2002; Tomasi 2010, 2014) y/o para el guardado de elementos que no necesitan aislarse de la intemperie. La misma función podrían haber cumplido espacios que en el SB de QM4 se ubican a modo de "antepatios" de algunos recintos tipo 1. De manera similar, los muros que conforman anexos del tipo 1 podrían haber sido construidos, en muchos casos, para generar pequeñas áreas reparadas asociadas a los recintos techados, tal vez destinadas a delimitar un fogón, como es el caso de parapetos asociados a viviendas prehispánicas en Lípez (cfr. Nielsen 2001).

Los recintos clasificados como 2.C constituyen espacios reducidos que se ubican sin asociación directa con otros espacios construidos, y en sectores directamente vinculados con evidencias de explotaciones mineras. Si bien no se han observado en su interior, en superficie, elementos que remitan a este tipo de labores, surge como hipótesis que hayan servido como reparo para personas abocadas a actividades de minería o bien para el acopio o depósito de materiales. Futuras excavaciones podrían arrojar luz sobre este aspecto.

La mayor parte de los recintos que hemos clasificado como 2.D presentan características arquitectónicas y espaciales a partir de las cuales los interpretamos como corrales para ganado. Algunos de ellos conforman UAC en las que un pequeño recinto se ubica en el vértice interno de uno más grande (Modalidad III). Pensamos que estos pequeños espacios podrían haber sido utilizados para separar a los animales pequeños o débiles del resto del rebaño, tal como lo hacen pastores puneños en la actualidad mediante los llamados "chiqueros" (cfr. Göbel 2002; Tomasi 2010). En AN prácticamente todos los recintos que podrían haber funcionado como corrales se disponen hacia los márgenes de AN1, o en sectores más alejados, como AN4. En QM4 este tipo de construcciones solo se registraron en el SD. Por otra parte, el Patio 2 del CA1 en QM4 es un amplio espacio que habría constituido la cancha de matanza de ganado que se menciona en fuentes escritas de los años 1776 y $1778^{10}$ (Angiorama et al. 2018a; Giusta 2019).

\section{Configuración de los espacios construidos y modos de habitar}

La unidad básica de vivienda habría consistido en una UAS techada, en algunos casos acompañada por un espacio externo descubierto, ya sea parcial o totalmente delimitado. Como vimos, aunque muchas viviendas pudieron constar de un único espacio cubierto, en prácticamente todos los conjuntos que presentan construcciones que hemos interpretado como unidades habitacionales, éstas se articularon con uno o más espacios construidos y/o estructuras vinculados a prácticas que habrían permitido la reproducción social de los habitantes: reparos para fogones, patios, recintos que habrían funcionado como cocinas externas, hornos para elaborar pan o cocinar otro tipo de alimentos, y corrales. Los hornos se ubicaron en proximidad de las viviendas, la mayoría de las veces sin demasiadas restricciones físicas para su acceso, mientras que la mayoría de los corrales se ubican algo más distanciados, pero dentro de un ámbito de control doméstico. En este sentido, la mayoría de los CA habrían incluido elementos similares a los que disponen los pastores actuales de la puna en sus domicilios, es decir, habitaciones techadas que funcionan como dormitorios y depósitos, recintos pequeños sin techar en los que se coloca el fogón, horno, patio y corrales (cfr. Delfino 2001; Göbel 2002; Tomasi 2014; entre otros). Esto indicaría, para el caso de asientos mineros del período colonial como los de la localidad de Antiguyoc, un 
importante grado de autonomía en el modo en que habitaba la población indígena y mestiza, ya que habrían reproducido ciertas lógicas vinculadas a su hábitat campesino pastoril. Tal situación exhibe diferencias claras con respecto a la mayoría de los campamentos mineros que proliferarían luego, durante el período Republicano, en los que la lógica empresarial vinculada a un modelo industrial-capitalista impuso patrones de asentamiento basado en habitaciones dispuestas a modo de "cuarteles" con una única cocina-comedor para todos los trabajadores (cfr. Delfino et al. 2014; Sironi 2015; Meléndez 2016).

QM4: la hacienda de Nuestra Señora del Carmen de Antiguyoc

Planteamos que en este sitio se encontraba la hacienda que Fernando Dávalos instaló alrededor de los años 1774-75, sobre la base de algunas correspondencias arquitectónicas entre el Sector A, en particular el CA1, y el asentamiento descripto en su testamento (Giusta 2019). Por otro lado, sobre la base de los análisis llevados a cabo fue factible comprobar que el mencionado conjunto reúne características singulares desde el punto de vista arquitectónico y espacial. Allí destacan las construcciones en adobe, los patios internos y el Patio 2 (cancha). La documentación escrita señala, además de los espacios que hemos podido constatar arqueológicamente (viviendas, patios, cancha de matanza), una tienda, una cocina, un cementerio y un espacio de procesamiento metalúrgico ("fragua" o "herrería") (Ulloa 2005; Giusta 2019).

Aunque en el testamento de Dávalos no se describen construcciones más allá de las que hemos mencionado, se alude indirectamente a la presencia de trabajadores de las encomiendas de Casabindo y Cochinoca dedicados a la minería, por lo que es posible pensar que residían en el lugar, al menos temporalmente. En este sentido, es factible que las edificaciones de los sectores B, C y D correspondan a dichas viviendas. Allí se encuentran recintos pequeños y de confección expeditiva que estuvieron techados con rocas; salvo un posible caso, no se construyeron hornos; no se edificaron UA que incluyan desde el momento de la construcción dos recintos cubiertos y tampoco se observaron subdivisiones posteriores; la mitad de las instalaciones presentan un único espacio techado y no muestran, salvo algunas excepciones, conformaciones integradas por numerosos espacios construidos. Todo esto indica que se trata de sectores de baja densidad ocupacional y quizás ocupados transitoriamente.

\section{AN: Asiento minero y Viceparroquia de Antiguyoc}

El poblado que se formó en la quebrada de Antiguyoc en proximidad de las vetas auríferas constituyó la sede de la Viceparroquia colonial entre 1777 y 1824 (Vergara 1942; Giusta 2019). En AN1 es posible diferenciar algunos sectores que presentan características distintivas. En primer lugar, si trazamos un eje imaginario en sentido norte-sur que pase por la iglesia, hacia el este se ubican CA que reúnen atributos que los distinguen de otras construcciones del poblado, tanto desde el punto de vista arquitectónico como espacial. Nos referimos a los CA 8, 9, 10, 11 y 12. Por un lado, destaca su disposición con diseño en "L", orientados hacia el frente y hacia uno de los laterales de la iglesia, ocupando el espacio directamente relacionado con este ámbito. A su vez, algunos presentan una disposición de manera alineada y paralelos entre sí, al parecer procurando un trazado "a cordel" (figura 18).

El CA8, ubicado frente a la iglesia, es el único que presenta un patio central totalmente circunscripto con respecto al exterior; y todos los recintos tipo 1 que lo integran conforman UAC, una de ellas con la mayor superficie del poblado. Por otra parte, espacios de otros CA presentan rasgos que podrían estar relacionados con arquitecturas religiosas. El recinto R1 del CA11, con 


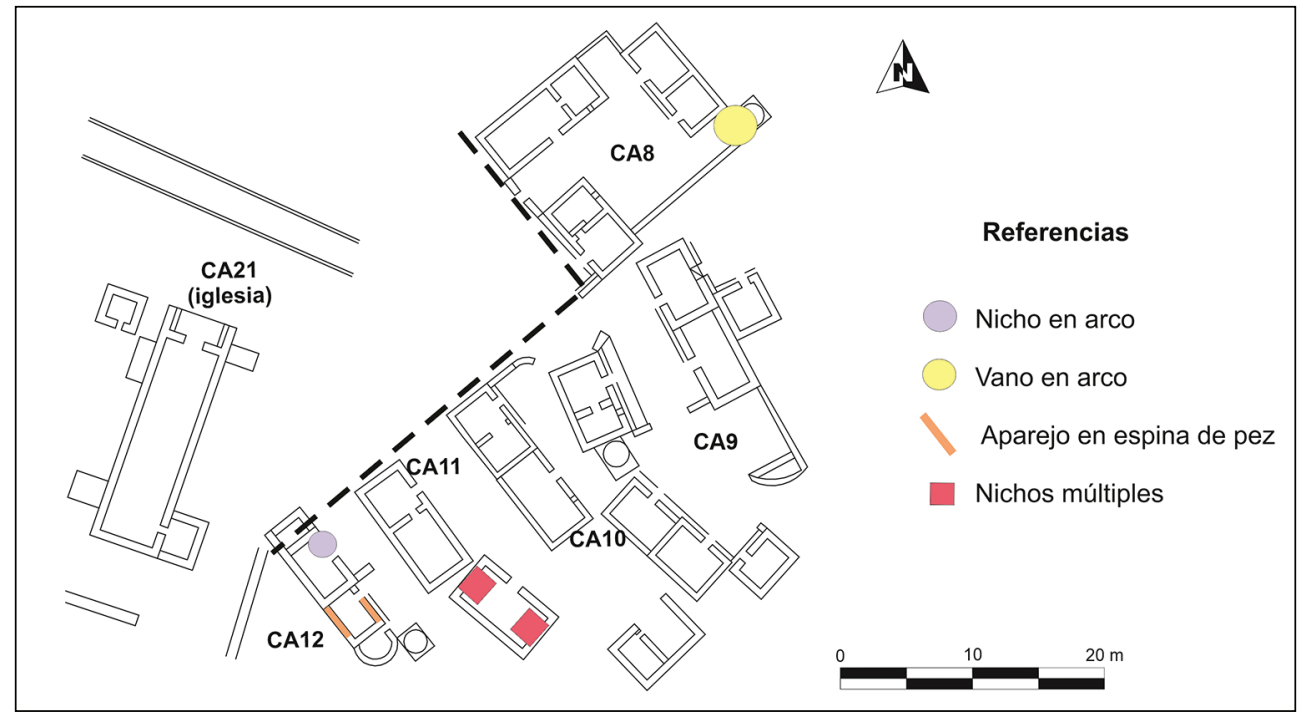

Figura 18. Disposición de los CA 9, 10, 11 y 12 de AN1, y ubicación de rasgos arquitectónicos singulares. Fuente: elaboración del autor

su gran cantidad de nichos y la manera particular en que se disponen, podría haber funcionado como una primigenia capilla u oratorio. El R1 del CA12 presenta el único nicho en arco de los sitios aquí analizados, y R2 exhibe muros con aparejos que remiten a la técnica de espina de pez, recurso que se vincula con edificaciones religiosas (iglesias, casas parroquiales, etc.) en sitios de España y América (Angiorama et al. 2018b; Giusta 2019). Por otra parte, varios recintos del CA11 y el R1 del CA12 contienen poyos tipo cama en su interior, por lo que podrían haber sido utilizados como espacios de vivienda para el personal eclesiástico. ${ }^{11}$ En síntesis, los CA mencionados hasta aquí forman parte de un sector cuyo desarrollo implicó una particular disposición espacial (al parecer en parte planificada, intentando otorgar una mayor regularidad al asentamiento) y la inclusión de rasgos arquitectónicos que los diferencian del resto. Pensamos, por estos motivos, que esto podría estar señalando viviendas correspondientes a españoles y/o a autoridades civiles y religiosas mencionadas en diferentes fuentes escritas analizadas (Giusta 2019).

En cambio, hacia el oeste y el sur de la iglesia, las instalaciones no se presentan siguiendo un ordenamiento identificable entre ellas, y exhiben variadas asociaciones entre las construcciones, la mayoría con al menos dos recintos que estuvieron techados. Por otro lado, existen instalaciones que se ubican claramente hacia los márgenes de AN1, lo que además coincide con sectores de mayor altitud con respecto a la cota de la iglesia y sus alrededores.

Una propuesta sobre las interacciones sociales

Hillier y Hanson (1984) plantearon que las interacciones sociales entre habitantes de un asentamiento pueden ser abordadas a partir de su configuración espacial. Parten de la premisa de que la organización espacial es una función de la forma de solidaridad social, es decir, que es posible relacionar la configuración interna de un asentamiento y sus sectores con el grado de heterogeneidad social presente. Sobre esta base proponen dos modelos de asentamientos, cada uno con una lógica espacial diferente según las características y relaciones entre los ocupantes: uno denominado de "correspondencia", caracterizado por un asentamiento claramente sectorizado 
de acuerdo a grupos sociales o étnicos distintos; y otro de "no correspondencia", en el que un asentamiento no presenta demasiados límites internos, o bien promueve el encuentro entre sus habitantes ya que no buscan establecer diferencias entre ellos, tal vez producto de escasas o nulas diferencias sociales y/o étnicas.

Siguiendo esta propuesta, el Sector A de QM4 se presenta como un espacio claramente delimitado que podría estar señalando características relacionables a un sistema de correspondencia, ya que el hacendado Dávalos configuró un ámbito habitacional y productivo que lo separaba de las viviendas de los trabajadores indígenas. En especial el CA1, constituye un núcleo constructivo prácticamente cerrado y de amplias dimensiones, lo que, sumado a los componentes, técnicas constructivas, superficies destinadas a algunas UA y la vinculación entre espacios hacen de éste un lugar con marcadas diferencias con respecto al resto de las instalaciones. En primer término, a partir del registro y los análisis llevados a cabo, podemos señalar que en este sector las UAC de adobe con sobrecimientos de piedra (subtipo 1.A.m) destacan del resto por diferentes motivos. Por un lado, son las únicas edificaciones en las que se utilizó el adobe como componente constructivo principal en los muros. Además, una de las UAC es la única que está conformada por tres recintos, y a su vez se adosó hacia la parte posterior otra construcción de adobe vinculada a la anterior mediante un vano, resultando en una comunicación interna entre cuatro recintos que estuvieron techados. Este constituye un aspecto singular ya que es el único caso registrado en ambos sitios, mientras que, como hemos visto, el resto de las UAC contienen hasta un máximo de dos recintos cubiertos comunicados internamente. Por otro lado, estas unidades habitacionales de adobe, las que consideramos como la vivienda principal de Dávalos y su familia, representan las construcciones techadas de mayor superficie en ambos sitios y se orientan a un amplio patio (Patio 5) que, a su vez, presenta comunicación directa con otros espacios descubiertos (Patio 3 y Patio 7) a los cuales se orientan otras UA que estuvieron techadas (figura 16).

La presencia de recintos del tipo 2.A ("patios") en el CA1 también es particular, tanto en cantidad como en la superficie que ocupan, ya que de los catorce registrados en ambos sitios, seis se disponen allí, e incluyen a los más amplios. Como hemos señalado antes, al menos uno de ellos, el Patio 2, formaba parte de su emprendimiento ganadero como cancha de matanza, y constituye el espacio construido de mayor superficie en ambos sitios.

El sector nuclear que estamos describiendo (Sector A) se completa con los CA2 y 3, donde recintos de piedra, algunos de ellos con poyos tipo cama en su interior, podrían haber constituido las viviendas de la esclava y posiblemente del mayordomo y otros sirvientes y "criados" que aparecen en la documentación histórica (Rojas 1913; Ulloa 2005; Giusta 2019). De este modo, los espacios se dispusieron y articularon de manera tal que el propietario contaba con un núcleo constructivo multifuncional desde el cual podía ejercer control sobre personas y actividades productivas. A su vez el establecimiento pudo haber estado reproduciendo parte del modelo de vivienda colonial de las ciudades, vinculado a criollos o españoles, en el que era frecuente la construcción en adobe, la disposición de varios cuartos comunicados internamente y la presencia de varios patios.

En cuanto a los sectores B, C y D, en el apartado anterior señalamos características arquitectónico-espaciales que nos llevaron a proponer que allí se instaló población transitoria y quizás rotativa que constituía la mano de obra minera y ganadera. Éstas pueden sintetizarse en una baja densidad constructiva (escasa cantidad de recintos, dispersos en una amplia superficie); baja superficie de espacios habitacionales cubiertos (promedio de 8,5 $\mathrm{m}^{2}$ en el Sector B, 3,3 $\mathrm{m}^{2}$ en el C y $5,6 \mathrm{~m}^{2}$ en el D, en comparación con los 20,4 $\mathrm{m}^{2}$ del Sector A); técnicas constructivas expeditivas como en el caso de recintos de tipo 1.B (techo de piedra en falsa bóveda); baja o nula frecuencia de ampliaciones y/o remodelaciones (por ejemplo, la mitad de las instalaciones presentan un único espacio techado y no se encuentran en estos sectores UAC con dos recintos cubiertos, solo una mixta que involucra a un recinto de tipo 1.B); escasa presencia de rasgos arquitectónicos destinados a mejorar la habitabilidad interna (poyos tipo cama, tipo asiento, muros tipo mesa, etc.) y la casi 
nula presencia de hornos domésticos. De todas maneras, algunos CA ubicados en estos sectores, en especial en el B, presentan una mayor cantidad de espacios construidos y un mejor estado de conservación, lo que podría estar señalando residencias con ocupaciones más prolongadas y que incorporaron una mayor cantidad de personas.

En síntesis, el asentamiento que hemos denominado Quebrada del Maray 4 se habría conformado mediante la constitución de dos ámbitos claramente diferenciados: un casco de estancia o hacienda rural, esfera del hacendado español, su familia y sus sirvientes; y el espacio de vivienda de indígenas empleados como mano de obra, a modo de "ranchería de indios", asociadas directamente a los sectores de extracción aurífera. Dicha configuración estaría marcando relaciones sociales establecidas principalmente sobre la base de un vínculo propietario-trabajadores.

En AN, en cambio, los análisis llevados a cabo nos invitan a plantear el desarrollo de un asentamiento vinculado mayormente a un sistema de no correspondencia. A pesar de la variabilidad interna que hemos logrado registrar, no se observan diferencias demasiado contrastantes en aspectos constructivos y espaciales entre un conjunto arquitectónico determinado y el resto del sitio. Más bien, dicha variabilidad en las instalaciones permite ubicarlas en un gradiente que se conforma teniendo en cuenta cantidad de espacios techados y superficies ocupadas, modalidades constructivas, cantidad de rasgos arquitectónicos, entre otros, donde una constante es la edificación de espacios cubiertos que responden a las características englobadas bajo el subtipo 1.A.r (muros de piedra y argamasa de barro a doble hilada, con techumbre a dos aguas) con plantas mayormente rectangulares.

La mayoría de los conjuntos, si bien pueden presentar espacios centrales a modo de patios, éstos no se encuentran totalmente aislados del exterior. Con excepción del CA8, el resto de las construcciones en las que es factible desarrollar actividades de cocina u otras labores domésticas, ya sea en un recinto al aire libre o mediante un horno, presentan una comunicación o visualización irrestricta desde el espacio exterior. Esto no implica que hayan sido lugares de libre acceso para todas las personas del poblado (no debemos descartar restricciones sociales), pero al menos no se buscó limitarlos del todo físicamente.

Los CA que se encuentran hacia el este de la iglesia dispuestos de manera alineada, los cuales hemos asociado principalmente con la instalación de autoridades eclesiásticas, y quizás también civiles, se ubican "de espaldas" entre sí y se orientan hacia lugares de circulación que intermedian entre los recintos y el espacio externo más general, pero no se encuentran aislados constructivamente del resto de los conjuntos. Por otro lado, exhiben similitudes constructivas con el resto de las instalaciones, matizadas por ciertos rasgos arquitectónicos y espaciales singulares que hemos indicado en el apartado anterior (e.g.: aparejos en espina de pez, vano en arco, cantidad/ ubicación de nichos, disposición de las UA).

Los CA ubicados hacia el oeste de la iglesia presentan características similares a los anteriores y entre sí, no solo en cuanto a componentes y técnicas constructivas. Por ejemplo, en casi todos ellos existen UAC, es decir la manifestación de voluntades constructivas destinadas a generar más de un ámbito interno, entre los cuales se diferencia el CA4 por ser el único en este sector en el que existe una UAC correspondiente a la Modalidad II, pero que a su vez la hace comparable a los CA7 y 8, dispuestos hacia el este de la iglesia. También podemos señalar una regular distribución y frecuencia de rasgos arquitectónicos como poyos tipo cama, tipo asiento, nichos, estantes y muros tipo mesa.

Tal vez, un contraste mayor se dé entre las instalaciones mencionadas anteriormente y aquellas que se ubican hacia los márgenes del conglomerado y a una mayor altitud, ya que constituyen CA más reducidos que presentan cada uno un único recinto techado, sin UAC. Sin embargo, éstos corresponden también al subtipo 1.A.r, contienen similares frecuencias de rasgos arquitectónicos (exceptuando el CA13, en el que no se registró ninguno) e incluso algunos ocupan una amplia superficie, como el caso del CA15. 
Las características señaladas estarían marcando relaciones sociales establecidas principalmente sobre la base de vínculos autoridades-gente "del común". En este caso, la diferenciación entre segmentos sociales o étnicos no se habría manifestado mediante el aislamiento físico o el control, sino a través de ciertas características diferenciales de la arquitectura, como el modo de disponer las viviendas y rasgos de tradición europea. Tal vez, el CA8, con sus recintos y horno completamente delimitados con respecto al exterior, sea el único que responda a características opuestas, es decir compatible con un sistema de correspondencia.

En este sentido, las diferencias más claras se habrían manifestado entre los habitantes indígenas/mestizos y los escasos españoles que habrían habitado allí, además de los clérigos que se hacían presentes como máximo una o dos veces al año y permanecían solo unos pocos días (Giusta 2019).

\section{AGRADECIMIENTOS}

Las investigaciones fueron posible gracias al apoyo humano y económico de diferentes personas e instituciones, en especial: Carlos Angiorama y todos/as los/las compañeros/as del equipo "Arqueología y Etnohistoria de la Puna Norte"; los y las habitantes de las localidades de la Puna de Jujuy en las que llevamos a cabo tareas de campo; Consejo Nacional de Investigaciones Científicas y Técnicas; Instituto de Arqueología y Museo (Facultad de Ciencias Naturales e IML, Universidad Nacional de Tucumán); Instituto Superior de Estudios Sociales (ISES-CONICET); Fondo para la Investigación Científica y Tecnológica. Agradezco también los valiosos comentarios y sugerencias de las evaluaciones, los cuales contribuyeron a mejorar el presente escrito.

\section{NOTAS}

1 "Techos de tejas coloniales, impecables paredes blanqueadas a la cal, trabajados balcones limeños en casas de dos pisos o notables portadas labradas en piedra conforman nuestro retrato estereotipado" (Rivet y Tomasi 2009:2). A ello podemos agregar también la presencia de numerosos cuartos o ambientes (cfr. Zarankin 1999).

2 Archivo de Tribunales de Jujuy (ATJ), Carpeta 50, Legajo 1653, año 1776.

3 Consideramos como conjuntos arquitectónicos a asociaciones de espacios construidos que se encuentran interrelacionados por contacto, proximidad, o la circulación que los une, de manera tal que pueden apreciarse como espacios integrados (Morris 1987; Lema 2012).

4 Principalmente sedimentitas ordovícicas con metamorfismo de muy bajo grado, pertenecientes a la Formación Acoite (Coira et al. 2004).

5 A partir de allí las dimensiones son más variables, lo que deja sin utilidad los intervalos de $3 \mathrm{~m}^{2}$.

6 ATJ, C.50, L.1653, año 1776.

7 Algunas entradas formatizadas de piques o socavones ubicados en la quebrada de Antiguyoc cuentan con nichos en sus muros. De la misma manera, estos rasgos fueron registrados en bocaminas de otros sitios mineros coloniales como el cercano Ajedrez y San Antonio del Nuevo Mundo, Lípez (cfr. Cruz et al. 2012).

8 Su presencia es escasa o nula en la mayoría de los sitios con ocupaciones coloniales de nuestra área de estudio (Angiorama et al. 2015, 2018a). Esto contrasta con el panorama registrado para ciudades de fundación hispana (en su mayoría ubicadas en tierras bajas), en las que fue recurrente el uso de adobes y tapias para la construcción de viviendas.

9 El término permeabilidad es usado aquí para referir a la accesibilidad que presenta cada nodo con respecto al exterior y puede cuantificarse a partir de la cantidad de pasajes o puertas que es necesario atravesar para acceder a un nodo desde el exterior o viceversa. En este sentido, un nodo menos permeable tendrá una mayor "privacidad" con respecto al exterior, ya que su accesibilidad es menor. En los gráficos gamma, la permeabilidad o accesibilidad es representada a partir de niveles jerárquicos (Blanton 1994). 
10 ATJ, C.50, L.1653, año 1776; Archivo Histórico de Jujuy (AHJ), Colección del Marqués, Carpeta 57, año 1778.

1 En uno de los documentos analizados se hace mención a la casa del cura, la cual podría haber correspondido a algunos de estos espacios (AHJ, Colección del Marqués, C. 57, año 1778).

\section{FUENTES PRIMARIAS}

Archivo Histórico de Jujuy, Colección del Marqués, Carpeta 57, año 1778: “Depósito de los bienes de Don Fernando Dávalos, y entrega de ellos a sus acreedores Don Luis de la Zerda y otros".

Archivo de Tribunales de Jujuy, Carpeta 50, Legajo 1653, año 1776: “Testamentaria de Fernando Dávalos”.

\section{BIBLIOGRAFÍA}

Albeck, M. E. y S. Palomeque

2009. Ocupación española de las tierras indígenas de la puna y ‘raya del Tucumán’ durante el temprano período colonial. Memoria Americana 17(2): 173-212.

Albeck, M. E. y M. Ruiz

2003. El Tardío en la Puna de Jujuy: Poblados, Etnias y Territorios. Cuadernos FHYCS-UNJU20: 199-221.

Alonso, R. y J. Viramonte

1987. Geología y Metalogenia de la Puna. Estudios geológicos 43(5-6): 393-407.

Angelelli, V.

1984. Yacimientos metalíferos de la República Argentina, Vol. I. Instituto de GeologíaAplicada, Universidad Nacional de La Plata.

Angiorama, C. y F. Becerra

2012. El oro de la Puna: lavaderos, socavones y mineros en el período colonial. Arqueología de la minería aurífera del extremo norte de la Puna de Jujuy (Argentina). Vestigios, Revista Latino-Americana de Arqueología Histórica 6(1): 50-80.

2014. Como en ella jamás ha habido minas... Minería y metalurgia en la Puna de Jujuy durante momentos prehispánicos tardíos. Relaciones de la Sociedad Argentina de Antropología 39: 313-332.

2017. Reverberatory furnaces in the Puna of Jujuy, Argentina, during colonial times (from the end of the 16th to the beginning of the 19th century A.D.). Journal of Anthropological Archaeology 48: 181-192.

Angiorama, C., F. Becerra y J. Pérez Pieroni

2015. El mineral de Pan de Azúcar. Arqueología histórica de un centro minero colonial en la Puna de Jujuy (Argentina). Chungara 47(4): 603-619.

Angiorama, C., M. Giusta, M. F. Becerra y M. J. Pérez Pieroni

2018a. "La furia de buscar el oro": los asientos mineros del siglo XVIII y XIX en la Puna de Jujuy, Argentina. Memoria Americana 26(2): 8-26.

2019. Minería aurífera en el noroeste argentino: el caso de Timón Cruz (Santa Catalina, Jujuy, Argentina). Revista de Arqueología Histórica Argentina y Latinoamericana 13(2): 1-24.

Angiorama, C., J. Pérez Pieroni, F. Becerra y M. Giusta

2018b. Cambios y continuidades en la Puna de Jujuy (actual Argentina) durante la colonia. Población \& Sociedad 25(1): 5-43. 
Relaciones de la Sociedad Argentina de Antropología 46 (1), enero-junio 2021: 15-55

Assadourian, C. y S. Palomeque

2015. Los circuitos mercantiles del «interior argentino» y sus transformaciones durante la guerra de la independencia (1810-1825). Cuadernos de Historia. Serie economía y sociedad 13/14: 37-58.

Bárcena, R. y D. Schávelzon

1991. El Cabildo de Mendoza: arqueología e historia para su recuperación. Municipalidad de Mendoza.

Becerra, M. F.

2012. Cruces entre la Arqueología y la Historia. Hornos, socavones y registros: las prácticas minerometalúrgicas coloniales en la Puna de Jujuy a través del complejo Fundiciones 1 (Rinconada, Jujuy, Argentina). Población y Sociedad 19: 5-39.

2014a. "Para labrar y poblar..." Prácticas minero-metalúrgicas en la Puna de Jujuy durante el período colonial (siglos XVII-XVIII). Tesis Doctoral inédita, Facultad de Filosofía y Letras, UBA [En línea] [Consultado el 8 de mayo de 2015] Disponible en: http://repositorio.filo.uba.ar/handle/filodigital/4330

2014b. Para que "creciera el pueblo como Potosî": la minería en la puna de Jujuy durante el período colonial. Estudios Atacameños 48: 55-70.

Becerra, M. F. y D. Estruch

2016. "No soy sino un juez de farsa expuesto a la inclemencia de todos los provincianos": Minería y conflictos jurisdiccionales en torno al Subdelegado del Partido de la Puna, Jujuy a finales del siglo XVIII. Cuadernos del Instituto Nacional de Antropología y Pensamiento Latinoamericano 3(1): 62-80.

Bianchi Villelli, M.

2009. Cambio social y prácticas cotidianas en el orden colonial. Arqueología Histórica en Floridablanca (San Julián, Argentina, Siglo XVIII). South American Archaeology Series No 10. Oxford, BAR.

Biró de Stern, A.

1945. Aspectos arqueológicos de una población hispano-indígena descubierta en el Chaco. Anales del Instituto de Etnología Americana VI: 103-115. Mendoza, Universidad Nacional de Cuyo.

Blanton, R. E.

1994. Houses and households: a comparative study. Plenium Press.

Boman, E.

[1908] 1991. Antigüedades de la región andina de la República Argentina y del desierto de Atacama. Universidad Nacional de Jujuy.

Buscaglia, S., M. Bianchi Villelli, L. Starópoli, C. Bosoni, S. Carelli y J. Alberti

2012. Arqueología histórica en Península de Valdés. Primeros abordajes históricos y arqueológicos al fuerte San José (1779-1810). Revista de Arqueología Histórica Argentina y Latinoamericana 6: 11-43.

Cabanettes, C. y L. Amans

1891. Memoria de la expedición por las regiones auríferas del norte de la provincia de Jujuí. Buenos Aires, Imprenta y Librería de Mayo.

Carmignani, $\mathrm{M}$.

2018. La vivienda de patios como patrimonio urbano constitutivo de la identidad regional latinoamericana. Designia 6 (1): 79-97.

Carrió de la Vandera, A.

[1773] 1942. El Lazarillo de ciegos caminantes. Desde Buenos Aires hasta Lima. Buenos Aires, Ediciones argentinas Solar.

Carrizo, J. A.

1935. Cancionero Popular de Jujuy. Editorial Sic. 
Marco NicolÁs GiUSTA - Modos de CONSTRUIR Y HABITAR DURANTE MOMENTOS TARDOCOLONIALES EN LA PUNA ...

Castro, V., F. Maldonado y M. Vásquez

1991. Arquitectura del "Pukara" de Turi. Actas del XII Congreso Nacional de Arqueología Chilena: 79-102. Temuco.

Ching, F.

1996. Diccionario Visual de Arquitectura. México, Ed. Gustavo Gili.

Cobo, B.

[1653] 1964. Historia del Nuevo Mundo. Madrid, Ediciones Atlas, Biblioteca de Autores Españoles.

Cohen, L.

2010. Prácticas sociales, estrategias de visibilidad y construcción de la cartografía social durante el lapso ca. 1000-1500 AD en Antofagasta de la Sierra, Catamarca. Perspectivas desde el sitio Peñas Coloradas 3 cumbre. Tesis doctoral inédita, Universidad de Buenos Aires.

Coira, B., P. Caffe, A. Ramírez, W. Chayle, A. Díaz, S. Rosas, A. Pérez, B. Pérez, O. Orozco y M. Martínez 2004. Hoja Geológica 2366-I/2166-III, Mina Pirquitas. 1:250000. Boletín N ${ }^{o} 269$. Buenos Aires, Servicio Geológico Minero Argentino.

Criado Boado, F. y P. Mañana Borrazás

2003. Arquitectura como materialización de un concepto. La espacialidad Megalítica. Arqueología de la Arquitectura 2: 103-111.

Cruz, P., A. Nielsen, F. Téreygeol, J. P Deroin e I. Guillot

2012. La pacificación del mineral. Cerro Lípez, un enclave minero en la contienda sobre el Nuevo Mundo. Vestigios. Revista Latino-Americana de Arqueología Histórica 6(1): 11-44.

De Feo, C., A. M. Fernández y M. G. Raviña

2007. Las cabeceras del Río Grande de San Juan y sus relaciones con áreas vecinas durante los últimos momentos del desarrollo cultural prehispánico. Cuadernos de la Facultad de Humanidades y Ciencias Sociales 32: 135-149.

Delfino, D.

2001. Of pircas and the limits of society: ethnoarchaeology in the Puna, Laguna Blanca. Catamarca, Argentina. En L. Kuznar (ed.), Ethnoarchaeology of Andean South America: Contributions to archaeologicalmethod and theory: 116-137. International monograph in prehistory, Ethnoarchaeological series 4. Michigan, Ann Harbor.

Delfino, D., M. Quesada y S. Dupuy

2014. El ciclo del cobre en Minas Capillitas (Provincia de Catamarca, Argentina) en la segunda mitad del siglo XIX: tensiones entre lógicas productivas, escalas tecnológicas y unidades sociales. Estudios Atacameños 48: 119-140.

Domínguez, M. A.

1948. La vivienda colonial porteña. Anales del Instituto de Arte Americano e Investigaciones Estéticas 1: $65-86$.

Faberman, J. y C. Taboada

2018. ¿"Lules nómades" " “lules sedentarios”? Sociedades indígenas, movilidad y prácticas de subsistencia en la llanura santiagueña prehispánica y colonial (Santiago del Estero, Argentina). Andes, Antropología e Historia 29(2): 1-24.

Ferguson, T. J.

1996. Historic Zuni architecture and society: An archaeological application of space syntax. Anthropological papers of the University of Arizona, $\mathrm{N}^{\circ} 60$. 
Relaciones de la Sociedad Argentina de Antropología 46 (1), enero-junio 2021: 15-55

Fisher, J.

2000. La producción metalífera. En A. Castillero Calvo (dir.) y A. Kuethe (co-dir), Historia general de América Latina, Tomo III (1): 151-175. Madrid, UNESCO-TROTA.

Gasparini, G. y L. Margolies

1977. Arquitectura Inka. Caracas, Centro de Investigaciones Históricas y Estéticas, Facultad de Arquitectura y Urbanismo, Universidad Central de Venezuela.

Gil Montero, R.

1997. Unidades domésticas con residencias múltiples: Puna de Jujuy (Argentina), fines del siglo XVIII. Andes 8: 47-76.

2004. Caravaneros y transhumantes en los Andes meridionales. Población y familia indígena en la puna de Jujuy. 1770-1870. Lima, Instituto de Estudios Peruanos.

Gisbert, T. y J. de Mesa

1997. Arquitectura andina (1530 -1830). La Paz, Embajada de España en Bolivia.

Giusta, M.

2019. Modos de construir y habitar en la Puna de Jujuy. Un abordaje desde la Arqueología Histórica en la localidad de Antiguyoc (ca. 1774-1824), provincia de Jujuy, Argentina. Tesis Doctoral inédita, Facultad de Ciencias Naturales e IML, Universidad Nacional de Tucumán.

Göbel, B.

2002. La arquitectura del pastoreo: uso del espacio y sistema de asentamientos en la Puna de Atacama (Susques). Estudios Atacameños 23: 53-76.

Gramajo de Martínez Moreno, A.

1976. La primitiva ciudad de San Miguel de Tucumán en Ibatín. Estudio histórico y arqueológico. Relaciones de la Sociedad Argentina de Antropología 10: 141-165.

Gutiérrez, R.

1983. Arquitectura y Urbanismo en Iberoamérica. Madrid, Ediciones Cátedra.

Hardoy, J. y M. Gutman

2001. Construcción urbana y rural: sus aspectos ideológicos, sociales y económicos. En A. Castillero Calvo (dir.) y A. Kuethe (co-dir), Historia general de América Latina, Tomo III (2): 719-772. Madrid, UNESCO-TROTA.

Herr, C. y G. Rolón

2018. Registro documental e intervención patrimonial en la arquitectura religiosa de la Provincia de Jujuy. Anales del Instituto de Arte Americano e Investigaciones Estéticas “Mario J. Buschiazzo” 48(1):31-45.

Hillier, B.

1996. Space is the machine. A configurational theory of architecture. Londres, Space Sintax.

Hillier, B. y J. Hanson

1984. The Social Logic of Space. Cambridge, University Press.

Jamieson, R.

2003. De Tomebamba a Cuenca. Arquitectura y arqueología colonial. Quito. Abya-Yala.

Lema, C.

2004. Tebenquiche Chico en los siglos XVI y XVII. Tesis de licenciatura inédita, Escuela de Antropología, Facultad de Humanidades y Artes, Universidad Nacional de Rosario. 
2012. El Mineral de Incahuasi. Oro e historia en la encrucijada colonial. Tesis Doctoral inédita, Facultad de Humanidades, Universidad Nacional de Catamarca.

Lizárraga, R. de[1605]

1999. Descripción breve del Perú, Tucumán, Río de La Plata y Chile. Libro primero. Buenos Aires, Academia Nacional de la Historia.

Madrazo, G.

2005. Pacto étnico, rebelión y modernidad en el siglo XVIII. Andes 16: 27-44.

Mañana Borrazás, P., R. Blanco Rotea y X. Ayán Vila

2002. Arqueotectura 1: Bases teórico-metodológicas para una arqueología de la arquitectura. TAPA 25. España, Universidad de Santiago de Compostela.

Meléndez, A.

2016. La vida en Mina Dal (El Alto, Catamarca). Aproximaciones desde la arqueología. Comechingonia 20(2): 189-214.

Mignone, $\mathrm{P}$.

2014. Fuentes para la localización y el estudio de las minas históricas del Nevado de Acay, Departamento La Poma. Salta, Argentina. Memoria Americana. Cuadernos de Etnohistoria 22(1): 65-92.

Morresi, E.

1983. Muestrario de material arqueológico del contacto hispano-indígena en el "Lugar Histórico" de Concepción del Bermejo. En E. Morresi y R. Gutiérrez (eds.), Presencia hispánica en la Arqueología Argentina Vol. 1: 15-27. Argentina, Universidad Nacional del Nordeste.

Morris, C.

1987. Arquitectura y estructura del espacio en Huánuco Pampa. Cuadernos del Instituto Nacional de Antropología y Pensamiento Latinoamericano 12 (1): 27-45.

Muñoz Ovalle, I.

2014. Hurgando la vivienda andina a través de la historia: percepción y ocupación del espacio domésticoceremonial en los valles y altiplano en la región de Arica y Parinacota, Chile. Intersecciones en Antropología 15: 235-250.

Niell, P.

2019. Ibero-American Architecture and urbanism. En J. Lyons (ed.), The Oxford Handbook of the Baroque: 286-310. Oxford, University Press.

Nielsen, A.

1995. Architectural performance and the reproduction of social power. En J. Skibo, W. Walker y A. Nielsen (Eds.), Expanding Archaeology: 47-66. Salt Lake City, University of Utah Press.

2001. Evolución del espacio doméstico en el norte de Lípez (Potosí, Bolivia): ca. 900-1700 DC. Estudios Atacameños 21: 41-61.

Palomeque, S.

1995. Intercambios mercantiles y participación indígena en la "Puna de Jujuy" a fines del Período Colonial. Andes 6: 13-49.

2006. La Historia de los señores étnicos de Casabindo y Cochinoca (1540-1662). Andes 17: 139-194.

Parenti, R.

1988. Le tecniche di documentazione per una lettura stratigrafica dell'elevato. Archeologia e restauro dei monumento: $249-279$. 
Paz, G.

1997. Familia, linaje y red de parientes: la elite de Jujuy en el siglo XVIII. Andes 8: 145-174.

Pérez Pieroni, M. J.

2015. Prácticas productivas y tradiciones tecnológicas: la manufactura cerámica prehispánica tardía y colonial en la cuenca Sur de Pozuelos y el área de Santa Catalina, Puna de Jujuy, Argentina. Relaciones de la Sociedad Argentina de Antropología 40(1): 13-44.

2018. Tecnología cerámica de época colonial en la cuenca sur de Pozuelos y el área de Santa Catalina, puna de Jujuy, Argentina. Revista de Arqueología Histórica Argentina y Latinoamericana 12: 116-140.

Protzen, J. P.

2008. Arquitectura y construcción incas en Ollantaytambo. Perú, Fondo Editorial de la Pontificia Universidad Católica del Perú.

Quiroga, L.

1999. La construcción de un espacio colonial: paisaje y relaciones sociales en el antiguo valle de Cotahau (provincia de Catamarca, Argentina). En A. Zarankin y F. Acuto (eds.), Sed Non Satiata. Teoría Social en la Arqueología Latinoamericana Contemporánea: 273-287. Buenos Aires, Ediciones del Tridente.

2007. Arquitectura de la vivienda prehispánica y colonial. Una perspectiva comparativa en el área valliserrana del Noroeste Argentino. Actas del Congreso Internacional de Arquitectura Vernácula: 71-77.

Quisbert, P., C. Rivera y N. Vincent

2018. Un asiento minero en el norte de Potosí: San Miguel De Aullagas, entre encuentros y descubrimientos. En M. A. Muñoz (ed.), Interpretando huellas, arqueología, etnohistoria y etnografía de los Andes y sus tierras bajas: 149-165. Cochabamba, Grupo Editorial Kipus.

Raffino, R. (dir.)

1993. Inka. Arqueología, Historia y Urbanismo del altiplano andino. Buenos Aires, Corregidor.

Raffino, R. y A. Igareta

2003. Arqueología histórica en Argentina: cuadro de situación y perspectivas. Revista de Arqueología Americana 22: 7-23.

Raffino, R., C. Vitry y D. Gobbo

2004. Inkas y Chichas: identidad, transformación y una cuestión fronteriza. Boletín de Arqueología PUCP 8: 247-265.

Rapoport, A.

1990. The meaning of the built environment: a non-verbal communication approach. Tucson, University of Arizona.

Rivet, C.

2017. La vivienda en la primera San Miguel de Tucumán. En E. Noli (comp.), Revisitando Ibatín. Investigaciones históricas y arqueológicas: 119-146. Tucumán, Instituto de Arqueología y Museo, Universidad Nacional de Tucumán.

Rivet, C. y J. Tomasi

2009. De las expectativas a las concreciones. Imágenes sobre la vivienda en el Tucumán Colonial. Miradas desde la arqueología y la arquitectura. En XII Jornadas Interescuelas/Departamentos de Historia. Departamento de Historia, Facultad de Humanidades y Centro Regional Universitario Bariloche.

Rojas, R.

1913. Archivo Capitular de Jujuy, Tomo I. Buenos Aires, Imprenta de Coni Hermanos. 
Rolón, G.

2013. La vivienda popular riojana del ámbito rural: Patrones arquitectónicos y contexto social en los valles durante el Periodo republicano. Tesis doctoral inédita, Facultad de Filosofía y Letras, Universidad de Buenos Aires [En línea] [Consultado el 20 de septiembre de 2017] Disponible en: http://repositorio. filo.uba.ar/handle/filodigital/6015

Rowe, J.

1946. Inca culture at the time of the Spanish conquest. En J. Steward (ed.), Handbook of South American Indians, Vol. 2: 183-330. Smithsonan Institution.

Sánchez Albornoz, N.

1965. La extracción de mulas de Jujuy al Perú. Fuentes, volúmenes y negociantes. Estudios de Historia Social 1(19): 107-120.

Sánchez Zufiaurre, L.

2007. Técnicas constructivas medievales. Nuevos documentos arqueológicos para el estudio de la Alta

Edad Media en Álava. Leioa, Servicio editorial de la Universidad del País Vasco.

Schávelzon, D.

1988. Arqueología e historia de las Ruinas de San Francisco (1608-1861). Las Ruinas de San Francisco, arqueología e historia: 13-66. Publicación de la Municipalidad de Mendoza.

1994. Vivienda y vida cotidiana en el período colonial: una visión arqueológica. Seminario de Crítica 55: $1-31$.

1999. Arqueología de Buenos Aires. Buenos Aires, Emecé.

Schávelzon, D. y M. Magadán

1992. Potrero de Payogasta: la arquitectura de una ciudad incaica del Noroeste Argentino. En N. Saunders (ed.), Ancient America. Contributions to New World Archaeology: 173-188. Oxford, Oxbow Books, Park End Place.

Schiffer, M.

1999. The Material Life of Human Beings. Londres, Routledge.

Schilman, M. y D. Reisner

2011. Pircando con piedras en Susques y Rinconada. Usos y funciones, conocimientos y saberes a través de la experiencia. En J. Tomasi y C. Rivet (coords.), Puna y arquitectura. Las formas locales de la construcción: 57-70. Buenos Aires, CEDODAL.

Sgrosso, P.

1943. Contribución al conocimiento de la minería y geología del NOA. Boletín No53. Buenos Aires, Ministerio de Agricultura de la Nación.

Silva, M. B.

2001. La vivienda a patios de origen hispánico y su difusión en Iberoamérica. Actas del III Congreso Internacional del Barroco Americano: Territorio, Arte, Espacio y Sociedad: 875-896. Universidad Pablo de Olavide, Sevilla.

Sironi, O.

2015. Arqueología Histórica Industrial: explotaciones mineras en el Noroeste de Mendoza. Tesis doctoral inédita, Facultad de Filosofía y Humanidades, Universidad Nacional de Córdoba.

Suetta, J. M. y L. C. Alfaro de Lanzone

1979. Excavaciones arqueológicas en el Pukara de Rinconada, Jujuy. Antiquitas. Actas de Jornadas de Arqueología del NOA: 297-382. Universidad del Salvador, Buenos Aires. 
Relaciones de la Sociedad Argentina de Antropología 46 (1), enero-junio 2021: 15-55

Taboada, C. y J. Farberman

2014. Asentamientos prehispánicos y pueblos de indios coloniales sobre el río Salado (Santiago del Estero, Argentina): Miradas dialogadas entre la Arqueología y la Historia. Revista de Arqueología Histórica Argentina y Latinoamericana 8(1): 7-44.

Tapia, A.

2002. Indicadores biológicos y culturales de la conquista en el Delta del Paraná (siglos XVI y XVII). Relaciones de la Sociedad Argentina de Antropología 27: 357-374.

Tapia, A., M. Ramos y C. Baldasarre (eds.)

2006. Estudios de Arqueología Histórica. Investigaciones argentinas pluridisciplinarias. Museo Municipal de la Ciudad de Río Grande-Ediciones Bimce.

Tomasi, J.

2010. Geografías del pastoreo. Territorios, movilidades y espacio doméstico en Susques (Provincia de Jujuy). Tesis doctoral inédita, Facultad de Filosofía y Letras, Universidad de Buenos Aires [En línea] [Consultado el 05 de julio de 2016] Disponible en: http://repositorio.filo.uba.ar/handle/filodigital/843?show=full

2012. Lo cotidiano, lo social y lo ritual en la práctica del construir. Aproximaciones desde la arquitectura puneña (Susques, provincia de Jujuy, Argentina). Apuntes. Revista de estudios sobre patrimonio cultural 25(1): 8-21.

2014. De los pastoreos a la casa. Espacialidades y arquitecturas domésticas entre los pastores altoandinos (Susques, provincia de Jujuy). En A. Benedetti y J. Tomasi (comps.), Espacialidades Altoandinas. Nuevos aportes desde la Argentina, Tomo I: 257-299. Editorial de la Facultad de Filosofía y Letras, Universidad de Buenos Aires.

Tomasi, J. y J. Barada

2020. Patrimonios coloniales y republicanos. Caracterización de sus técnicas y materialidades en la provincia de Jujuy (Argentina). Gremium 7(14): 53-68.

Ulloa, M.

2005. Comerciantes, pulperos, hacendados y buscadores de oro. Españoles en la Puna de Jujuy a fines del Siglo XVIII. Actas del VI Congreso Internacional de Etnohistoria. Buenos Aires.

Urbina, A., L. Adán y C. Chamorro

2018. Materiales constructivos y arquitectura colonial del área fundacional de Valdivia (s. XVI-XIX). Revista de Arqueología Histórica Argentina y Latinoamericana 12: 934-962.

Vaquer, J. M.

2010. Habitando Cruz Vinto durante el período de Desarrollos Regionales Tardío. Tesis doctoral inédita, Universidad de Buenos Aires [En línea] [Consultado el 23 de agosto de 2017] Disponible en: http:// repositorio.filo.uba.ar/handle/filodigital/1652

2012. Apuntes para una semiótica de la materialidad. Comechingonia. Revista de Arqueología 16: 161-177.

Vergara, M. A.

1942. Estudios sobre historia eclesiástica de Jujuy. San Miguel de Tucumán, Instituto de Historia, Lingüística y Folklore, Universidad Nacional de Tucumán.

Wynveldt, F.

2005. Análisis espacial de los conjuntos arquitectónicos de Loma de los Antiguos de Azampay (Departamento de Belén, Catamarca). En C. Sempé, S. Salceda y M. Maffia (eds.), Azampay: Presente y pasado de un pueblito catamarqueño: 381-411. La Plata, Ediciones Al Margen.

Zapata Gollán, A.

1956. La construcción de la vivienda en Santa Fé La Vieja. Anales del Instituto de Arte Americano e Investigaciones Estéticas "Mario J. Buschiazzo" 9: 97-119. 
Marco NicolÁs GiUSTA - Modos de CONSTRUIR Y HABITAR DURANTE MOMENTOS TARDOCOLONIALES EN LA PUNA ...

1981. La urbanización hispanoamericana en el Río de la Plata. Santa Fe, Departamento de Estudios Etnográficos y Coloniales.

Zarankin, A.

1999. Casa Tomada: Sistema, Poder y Vivienda Familiar. En A. Zarankin y F. Acuto (eds.), Sed Non Satiata. Teoría Social en la Arqueología Latinoamericana Contemporánea: 239-272. Buenos Aires, Ediciones del Tridente. 
